Check for updates

Cite this: RSC Adv., 2018, 8, 31950

Received 27th May 2018

Accepted 28th August 2018

DOI: $10.1039 / \mathrm{c} 8 \mathrm{ra0} 0512 \mathrm{~g}$

rsc.li/rsc-advances

\section{Engineering docetaxel-loaded micelles for non- small cell lung cancer: a comparative study of microfluidic and bulk nanoparticle preparation $\uparrow$}

\author{
Yuchen Bao, ${ }^{a}$ Qinfang Deng, ${ }^{a}$ Yongyong Li (D) *b and Songwen Zhou (iD *a
}

\begin{abstract}
Bulk preparation of micelles has the drawbacks of facile formation of large aggregates and heterogeneous particle size distribution. Microfluidic technology has shown clear potential to address these challenges for robust nanomedicine applications. In this study, docetaxel-loaded PLGA-PEG-Mal-based micelles were prepared by microfluidics and dialysis methods and their physicochemical properties were analyzed. The biological behaviors of these micelles were also investigated in the non-small cell lung cancer (NSCLC) cell line A549 in vitro as well as in vivo. Encouragingly, the mean particle size of the micelles prepared by microfluidics (DMM) was smaller, with an average size of $72 \pm 1 \mathrm{~nm}$ and a narrow size distribution with a polydispersity index (PDI) of 0.072; meanwhile, micelles prepared by the dialysis method (DMD) had larger particle sizes (range, 102 to $144 \mathrm{~nm}$ ) and PDIs (up to 0.390). More importantly, significantly high drug loading was achieved using the microfluidic process. The $I_{50}$ value of DMM was lower than that of DMD. Whole-body fluorescence imaging of live mice showed that DMM achieved higher accumulation in tumors compared with DMD. DMM showed superior antitumor efficacy, with a tumor inhibition rate of 91.5\%. Moreover, pathological histology analysis revealed that no evident biological toxicity was caused by the micelles. In addition, Arg-Gly-Asp (RGD) was employed as a targeting agent on the basis of DMM to prepare targeting micelles, and the targeting micelles exhibited stronger cytotoxicity and obvious antitumor efficacy. In conclusion, DMM may have obvious clinical advantages for the treatment of NSCLC due to its optimized physiochemical properties. Therefore, microfluidic technology-based micelles are a promising platform as an effective drug delivery system for incorporating anticancer agents.
\end{abstract}

\section{Introduction}

Lung cancer is the leading cause of cancer death in adults aged 40 years or older and ranks second in terms of the number of new cancer cases in adults per year. ${ }^{1}$ Non-small cell lung cancer (NSCLC) accounts for more than $85 \%$ of all lung cancer cases. ${ }^{2}$ Although tyrosine kinase inhibitors have marked therapeutic effects, only limited patients who have EGFR mutations or ALK rearrangements can benefit from these drugs. Moreover, acquired drug resistance typically occurs within 9 to 12 months. ${ }^{3}$ To date, chemotherapy is still the first-line therapeutic regimen, and docetaxel (DTXL) is one of the most common anticancer drugs in clinical application. However, its clinical outcomes are significantly compromised due to a series of

${ }^{a}$ Department of Medical Oncology, Shanghai Pulmonary Hospital, Tongji University School of Medicine, Shanghai, 200433, China.E-mail: Zhou_songwen2092@126. com; Tel: +86-021-65115006

${ }^{b}$ Shanghai Tenth People's Hospital, The Institute for Biomedical Engineering \& Nanoscience, Tongji University School of Medicine, Shanghai, 200092, China. E-mail: yongyong_li@tongji.edu.cn; Tel: +86-021-65988029

† Electronic supplementary information (ESI) available. See DOI: 10.1039/c8ra04512g adverse reactions, such as bone marrow suppression, alopecia, skin reaction, nausea, vomiting, diarrhea, and liver function damage. $^{4}$

Nanomedicine-based drug-delivery systems have raised hopes of addressing these obstacles. ${ }^{5}$ Hydrophobic drugs can be encapsulated into carriers and can be protected from degradation to prolong their circulation times. This structure can also improve the apparent solubility of drugs to increase their stability in vivo and allow for controlled release as well as targeted delivery to avoid toxicity to normal organs. ${ }^{6-8}$ To date, a myriad of nanodrugs, including nanoparticles, micelles, and liposomes, have been investigated in preclinical trials. ${ }^{\mathbf{9 - 1 1}}$ Among these, micelles are generally considered to provide the most promising availability of drug delivery systems. ${ }^{12}$ Polymeric micelles are among the most promising candidates, and a few polymeric micelles, such as NK105, NC-6300, and Genexol-PM, are being tested in phase 2 trials with positive progress. $^{13,14}$

Although polymeric micelles are attractive drug delivery vehicles, their physical properties and delivery efficiency are strongly dependent upon their formulation conditions. ${ }^{15}$ For example, during the preparation of nanoparticles by the nanoprecipitation method, nucleation, growth, and agglomeration 

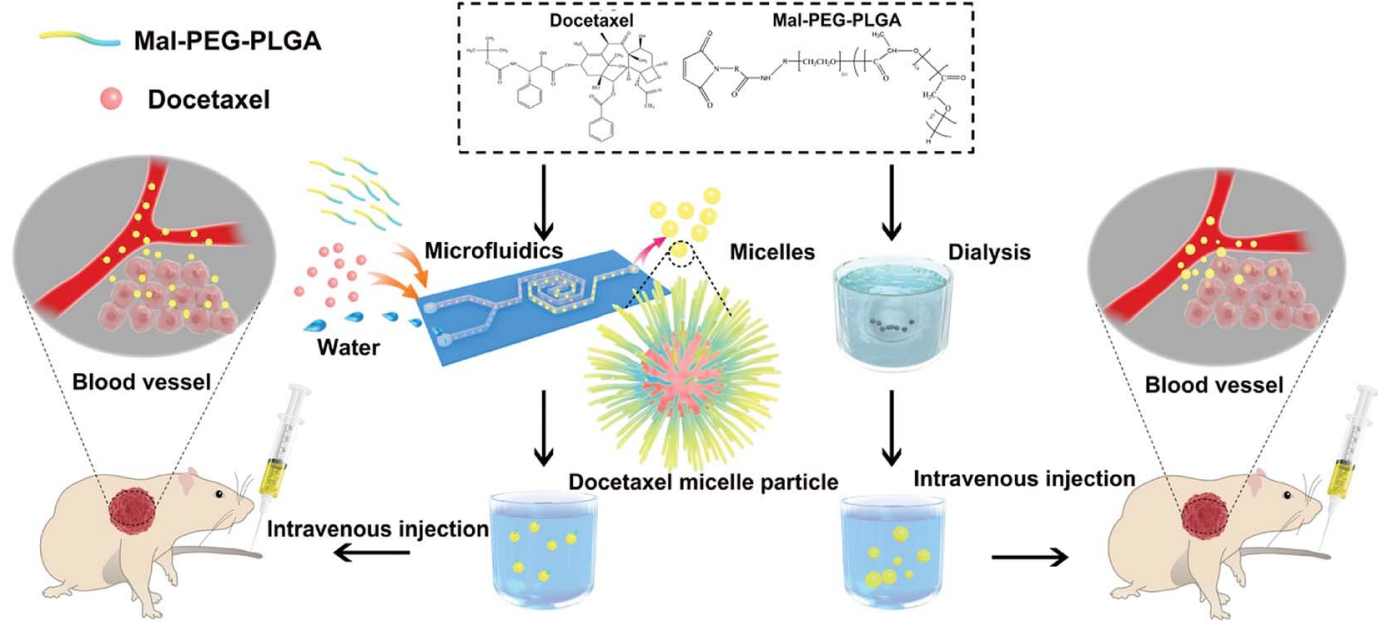

Scheme 1 Illustration of docetaxel-loaded micelles based on PLGA-PEG-Mal fabricated by microfluidics and bulk preparation. The treatment efficiencies of the different micelles were studied in NSCLC models in vitro and in vivo.

processes inevitably occur at the same time, resulting in high batch-to-batch variation in both the size and size distribution of the particles; this has limited their clinical translation. ${ }^{16}$ During the bulk preparation of polymeric micelles, the mixing timescale is longer than the characteristic timescale for chains to nucleate and grow. ${ }^{17,18}$ This heterogeneous environment usually leads to the formation of larger and inhomogeneous micelles without sufficient biological stability. ${ }^{19}$ In addition, it is known that the behavior of micelles within biological environments (blood circulation and passive or active targeting) greatly depends on their chemical composition and physical properties, such as size and polydispersity. ${ }^{20}$ For example, micelles with small size and narrow polydispersity typically contribute to greater tumor penetration. ${ }^{21}$ Furthermore, aggregation propensity during bulk preparation decreases the drug-loading efficiency and weakens the therapeutic efficacy. ${ }^{22}$ Taken together, it is highly favorable to obtain micelles that possess the desired physicochemical properties to achieve superior cancer therapeutic efficiency. ${ }^{23,24}$

Microfluidics is emerging in these circumstances. Microfluidics is an approach in which chemical reactions can be carried out on the microscale, based on nanoscale low-dimensional structures that control the fluid flow volume to picoliters or nanoliters during the reaction..$^{18}$ Compared with conventional methods, microfluidics yields homogeneous micelles with required characteristics, including favorable stability, tunable nanoparticle size, narrow size distribution, and relatively high drug loading. ${ }^{25-27}$ Microfluidics has been applied in many fields over the past decade, and it has emerged as a new fabrication technology to develop robust drug delivery systems. ${ }^{28-30}$ To the best of our knowledge, there have been few reports on microfluidicsbased micellar delivery systems for lung cancer research.

We conducted a comparative study of microfluidic and bulk preparations to develop micellar drug formulations for in vitro and in vivo NSCLC models (Scheme 1), with the intent to optimize the properties of drug-loading micelles based on microfluidic technology for potential clinical research. In addition to comparing the physicochemical properties and antitumor effects of micelles obtained from the two methods (bulk vs. microfluidics), minor polypeptides such as Arg-Gly-Asp (RGD) were introduced in the microfluidics process in order to tentatively explore the antitumor efficiency of micelles combined with a targeting polypeptide agent.

\section{Materials and methods}

\subsection{Materials and reagents}

Docetaxel was purchased from Beijing Zhongshuo Pharmaceutical Technology Development Co., Ltd. (Beijing, China). Cyclic SHRGD (RGDfK) was purchased from GL Biochem Ltd. (Shanghai, China). Dulbecco's Modified Eagle's Medium (DMEM) and fetal bovine serum were obtained from Gibco BRL (Grand Island, NY, USA). Poly (lactide-co-glycolide)- $b$-poly (ethylene glycol)-maleimide (Mal-PEG-PLGA, LA : GA molar ratio: $50: 50 ; M_{\mathrm{w}}: 5000: 30$ 000) was obtained from Akina, Inc. (West Lafayette, IN, USA). Fluorescein isothiocyanate (FITC) and Chlorin e6 (Ce6) were obtained from Sigma-Aldrich (St. Louis, MO, USA). MTT, DAPI, Annexin VFITC, and propidium iodide (PI) were purchased from Beyotime Biotechnology (Shanghai, China). All other reagents and solvents were ordered from Sinopharm Chemical Reagent Co., Ltd. (Beijing, China) and were of analytical or chromatographic grade. Balb/c nude mice (5 week-old) were purchased from SLRC Laboratory Animal Co., Ltd. (Shanghai, China). All mice were given distilled water and maintained at a temperature of $25 \pm 1{ }^{\circ} \mathrm{C}$, a relative humidity of $45 \% \pm 5 \%$, and a $10 \mathrm{~h} / 14 \mathrm{~h}$ light-dark cycle. This study was performed in strict accordance with the NIH guidelines for the care and use of laboratory animals (NIH Publication no. 85-23 Rev. 1985) and was approved by the Institutional Animal Care and Use Committee of Shanghai Pulmonary Hospital (Shanghai, China).

\subsection{Cell culture}

Human lung adenocarcinoma (A549) and Lewis lung carcinoma (3LL) cell lines were purchased from the Chinese Academy of 
Sciences of Shanghai Institutes for Biological Sciences Cell Resource Center (Shanghai, China). A549 and 3LL cells were grown in Dulbecco's Modified Eagle's Medium (DMEM) supplemented with 10\% fetal bovine serum (FBS) and antibiotics (penicillin $100 \mathrm{U} \mathrm{mL}^{-1}$ and streptomycin $100 \mu \mathrm{g} \mathrm{mL}^{-1}$ ). Cells were cultured at $37{ }^{\circ} \mathrm{C}$ in an incubator with $5 \% \mathrm{CO}_{2}$.

\subsection{Preparation of docetaxel micelles}

Docetaxel micelles were prepared by microfluidic (DMM) and dialysis (DMD) methods. PLGA-PEG-Mal ( $M_{\mathrm{w}}$ PEG/PLGA: 5000/ $30000)(10 \mathrm{mg})$ and docetaxel ( $2 \mathrm{mg}$ ) were dissolved in $4 \mathrm{~mL}$ of acetonitrile. During the process of micelle formation, the concentration of the polymers in solution is the most important factor. The critical micelle concentration (CMC) of PLGA-PEG ranges between $10^{-6}$ and $10^{-7} \mathrm{M}$, which is 100 times lower than that of DMM. ${ }^{31-33}$ An optimized $10: 2$ weight ratio of polymer to drug was chosen to simultaneously obtain maximized drug encapsulation and micelle stability (ESI Table $1 \dagger$ ). Then, the velocity of the acetonitrile phase used to dissolve PLGA-PEG-Mal and docetaxel was set at $40 \mu \mathrm{L} \mathrm{min}^{-1}$, with the velocity of the distilled water phase set at $360 \mu \mathrm{L} \mathrm{min}{ }^{-1}$. The organic phase and secondary water phase velocity at a ratio of 1 : 9 could afford relatively small particles, according to our preexperiment results (ESI Table $2 \dagger$ ). The reaction time was set to 40 min until the acetonitrile phase was finished; then, a light blue transparent micelle solution was acquired. The solution was transferred into a dialysis bag (molecular weight cutoff (MWCO) 8000 to 14000 ) and dialyzed against deionized water for $48 \mathrm{~h}$ to remove acetonitrile in solution. Next, the completed dialytic light blue transparent micelles were obtained. On the other hand, DMD was prepared by a dialysis method, which is a common method for micelle preparation. ${ }^{34}$ Briefly, $10 \mathrm{mg}$ of PLGA-PEG-Mal ( $M_{\mathrm{W}}$ PEG/PLGA; 5000/30 000) and $2 \mathrm{mg}$ of docetaxel were dissolved together in $4 \mathrm{~mL}$ acetonitrile; then, the mixed solution was dialyzed for $48 \mathrm{~h}$ in the reaction to form micelles (the MWCO of the dialysis bag was 100 to 500). After that, the solution was dialyzed again to remove acetonitrile, and the freeze-drying process was the same.

\subsection{Preparation of targeting micelles based on microfluidics}

To obtain targeting micelles, cyclic RGDfK was attached to the surface of DMM because the maleimide group of Mal-PEGPLGA could connect equimolar -SH groups of cyclic RGDfK in a typical Michael addition reaction. ${ }^{35}$ In the previous step of microfluidic-based micelles preparation, the acetonitrile phase was finished, which indicated that all the PLGA-PEG-Mal dissolved in the organic phase participated in the preparation process; thus, the specific amount of cyclic RGDfK was determined. Then, this mixed solution was stirred for $24 \mathrm{~h}$ at normal temperature with small additions of TEA (trimethylamine) and TCEP (tris(2-carboxyethyl) phosphine). After this process, the mixed solution was dialyzed for $48 \mathrm{~h}$ (the MWCO of the dialysis bag was 8000 to 14000 and the medium was secondary water) to remove the organic solvent, free copolymers, free drugs and free RGDfK. Afterwards, the solution was lyophilized at $-80{ }^{\circ} \mathrm{C}$ and stored for $24 \mathrm{~h}$; then, it was freeze dried (Martin Christ, ALPHA
1-4 LD plus, Germany) and stored for $12 \mathrm{~h}$ to obtain the solid phase. Finally, the targeting micelles were acquired and named targeting docetaxel-loaded micelles (TDMM). The cyclic RGDfK modification on the micelles was characterized by ${ }^{1} \mathrm{H}$ NMR spectroscopy (ESI Fig. $1 \dagger$ ). As shown in the ${ }^{1} \mathrm{H}$ NMR spectrum, the solvent peak of $\mathrm{CDCl}_{3}$ was found at $7.25 \mathrm{ppm}$ and the peak of tetramethylsilane (TMS) was observed at $0.07 \mathrm{ppm}$ (ESI Fig. $\left.1 \mathrm{~A}-\mathrm{C}^{\dagger}\right)$. The peaks at $1.45 \mathrm{ppm}$ and $2.0 \mathrm{ppm}$ are due to $H_{\mathrm{a}}$ and $H_{\mathrm{b}}$ in Mal-PEG-PLGA, respectively (ESI Fig. $1 \mathrm{~A} \dagger$ ). The peak at $3.57 \mathrm{ppm}$ was attributed to the $H_{\mathrm{c}}$ in maleimide, and the peak at $4.64 \mathrm{ppm}$ was ascribed to the $H_{\mathrm{f}}$ in PLGA. For RGDfK, the peaks at $1.26 \mathrm{ppm}$ and $3.75 \mathrm{ppm}$ were ascribed to $H_{\mathrm{a}}$ and $H_{\mathrm{b}}$, respectively. The characteristic peak at $1.75 \mathrm{ppm}$ was attributed to the $-\mathrm{SH}$ in RGDfK (ESI Fig. 1B $\dagger$ ). There were two characteristic peaks at $2.41 \mathrm{ppm}$ and $4.27 \mathrm{ppm}$, which can be attributed to $H_{\mathrm{b}}$ and $H_{\mathrm{a}}$ in RGD-labelled Mal-PEG-PLGA. This indicates that the $-\mathrm{SH}$ group of RGDfK was added to the maleimide of Mal-PEG-PLGA.

\subsection{Micelles characterization}

The size distributions and zeta potentials of the micelles were determined using a Zetasizer (Nano ZS90, Malwern Instruments, Ltd., UK). Transmission electron microscopy (TEM; JEM200CX, JEOL, Tokyo, Japan) was applied to observe the morphologies of the micelles. The drug loading and encapsulation efficiency were estimated using a high-performance liquid chromatography (HPLC) system (Waters, 2690-996, USA). The solid phase micelles were dissolved in methanol solution. The analysis process was performed on an ODS column (Diamonsil, $5 \mu \mathrm{m}, 250 \mathrm{~mm} \times 4.6 \mathrm{~mm}$ ) at $30{ }^{\circ} \mathrm{C}$. The mobile phase consisted of methanol and water $(65 / 35, \mathrm{v} / \mathrm{v}){ }^{36}$ The detection wavelength was set at $230 \mathrm{~nm}$, and the flow rate was $1.0 \mathrm{~mL} \mathrm{~min}^{-1}$. The calculation formulas of the docetaxel loading rate and encapsulation rate were determined previously by HPLC (ESI Fig. $2 \dagger$ ). The drug loading (DL\%) and encapsulation efficiency (EE\%) are expressed as the following equations:

$$
\mathrm{EE} \%=\frac{\text { Weight of docetaxel in micelles }}{\text { Weight of the initial docetaxel }} \times 100 \%
$$

$$
\mathrm{DL} \%=\frac{\text { Weight of docetaxel in micelles }}{\text { Weight of micelles containing docetaxel }} \times 100 \%
$$

\subsection{In vitro drug release studies}

The drug release experiments were performed by dialysis in PBS medium containing serum protein ( $\mathrm{pH} 7.4$ containing 10\% FBS). Specifically, solutions of docetaxel, DMD and DMM were

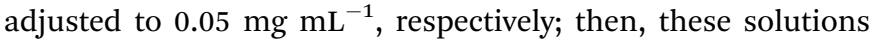
were placed in dialysis bags (MWCO $=8000 \mathrm{Da}$, Greenbird Inc., Shanghai, China). Each dialysis bag was sealed and immediately immersed in dialysis medium containing $0.5 \%$ Tween 80 to improve the solubility of docetaxel; then, the system was incubated at $37{ }^{\circ} \mathrm{C}$ with a shaking speed of $120 \mathrm{rpm}$. At scheduled time points, $1 \mathrm{~mL}$ of released sample was removed by 
suction and an equal volume was immediately replenished. These collected samples were later subjected to HPLC analysis.

\subsection{In vitro cellular uptake}

PLGA-PEG-Mal was labeled with fluorescein isothiocyanate (FITC) probe in advance to afford fluorescent micelles based on the reaction between the terminal hydroxyl of the copolymer and the isothiocyanate group of FITC, as previously reported. ${ }^{37,38}$ PLGA-PEG-Mal (10 mg), FITC (2 mg), and triethylamine $(200 \mu \mathrm{L})$ were dissolved in $5 \mathrm{~mL} N, N^{\prime}$-dimethylformamide (DMF). Then, the reaction was performed in a dark environment for $48 \mathrm{~h}$ at room temperature $\left(22^{\circ} \mathrm{C}\right.$ ) (ESI Fig. $\left.2 \mathrm{~A} \dagger\right)$. The reactant solution was dialyzed against water several times to remove the free FITC (MWCO 8000 to 14 000). Finally, FITC-PLGA-PEG-Mal was collected, followed by freeze-drying, and was then used to prepare micelles in the same way: namely, FITC-probed micelles by dialysis (FMD); FITC-probed micelles by microfluidics (FMM); and FITC-probed targeting micelles by microfluidics (FTMM). The fluorescence intensities of the three types of micelles were detected by an ultraviolet-visible (UV) spectrophotometer (LC-UV100S, Shanghai, China): $1.2 \mathrm{mg}$ of the three types of micelles were dissolved in PBS medium ( $\mathrm{pH}$ 7.4); then, equivoluminal solutions were subjected to UV detection, and the fluorescence intensity curves of the three groups were uniform (ESI Fig. 2B $\dagger$ ), indicating the stability of FITC-PLGAPEG-Mal. These FITC-probed micelles could be uptaken into cancer cells through endocytosis. ${ }^{39,40}$ Cellular uptake images were acquired via laser scanning confocal microscope (CLSM, Leica TCS SP5 II, Germany). A549 cells at $3 \times 10^{4}$ were plated in 6-well plates for $24 \mathrm{~h}$; then, $5 \mu \mathrm{g} \mathrm{mL} \mathrm{m}^{-1}$ of the three types of FITCprobed micelles ( $100 \mu \mathrm{L}$ per well) were added to the cells. After co-incubation for $2 \mathrm{~h}, 4 \mathrm{~h}$, and $6 \mathrm{~h}$, respectively, the culture medium was removed. The cells were washed three times with PBS and then fixed with $4 \%$ paraformaldehyde (v/v). After that, the cells were stained with DAPI and were washed with PBS as well. Cellular uptake images were acquired under the confocal microscope: green fluorescent vesicles represented micelles; blue fluorescence indicated the cell nucleus. Furthermore, the uptake efficiency was calculated by flow cytometry (BD FACSVerse, New Jersey, USA). In order to verify the targeting effects of RGDfK on $\alpha \mathrm{v} \beta 3$ integrin, the 3LL cell line with rare $\alpha \mathrm{v} \beta 3$ expression was applied as a control group. ${ }^{41}$ Cellular uptake images were also observed at $2 \mathrm{~h}, 4 \mathrm{~h}$, and $6 \mathrm{~h}$, respectively, and the uptake efficiency of the micelles was studied.

\subsection{Cytotoxicity studies}

The cytotoxicity activities of the micelles on A549 cells and 3LL cells were evaluated by the MTT method. Briefly, A549 and 3LL cells were placed at a density of $1 \times 10^{4}$ cells per well in 96-well plates and grown for 24 hours. Then, the cells were exposed to a series of free docetaxel (DTXL), blank micelles (BM), and DMD, DMM, and targeting docetaxel micelles prepared by microfluidics (DTMM) at docetaxel concentrations ranging from $1.25 \mathrm{nmol} \mathrm{mL}^{-1}$ to $80 \mathrm{nmol} \mathrm{mL}^{-1}$ (100 $\mu \mathrm{L}$ per well) for $48 \mathrm{~h}$. Each treatment group contained 6 repeat wells. After the incubation period, the micelles were removed and the cells were treated with $10 \mu \mathrm{L}$ of MTT solution for 4 hours. Then, the MTT solution was removed and $150 \mu \mathrm{L}$ of dimethyl sulfoxide (DMSO) was added to each well. The absorbance intensity was measured using a BioTek microplate reader at $490 \mathrm{~nm}$ to record the OD value, and the entire above procedure was defined as one independent experiment. The cell viability was calculated using the following equation:

$$
\text { Cell viability }(\%)=\frac{\mathrm{OD}_{\text {treated }}}{\mathrm{OD}_{\text {control }}} \times 100 \%
$$

$\mathrm{OD}_{\text {treated }}$ and $\mathrm{OD}_{\text {control }}$ represent the absorbance of the treatment and control cells, respectively.

\subsection{Detection of apoptosis}

The flow cytometry assay was used to quantify apoptosis of A549 cells. Cells $\left(1 \times 10^{6}\right.$ cells per chamber $)$ were seeded into six-well plates for $24 \mathrm{~h}$; each treatment group contained 3 repeat wells. DTXL, DMD, DMM, and DTMM were added at docetaxelequivalent doses of $20 \mu \mathrm{M}$ for $72 \mathrm{~h}$. Following incubation, cells were harvested using trypsinization and washed twice with PBS. According to the kit instructions, the cells were resuspended in $100 \mu \mathrm{L}$ of binding buffer (4\% paraformaldehyde); then, $5 \mu \mathrm{L}$ of Annexin V-APC and $5 \mu \mathrm{L}$ of PI were added..$^{42}$ The cells were incubated in the dark for $15 \mathrm{~min}$ at room temperature. Flow cytometry was performed to detect the results of the assay.

\subsection{In vivo imaging}

Biological distribution was investigated using a Night OWL LB 983 INVIVO imaging system. Drug-free chlorin e6 (Ce6)encapsulated micelles were prepared at a $\mathrm{Ce} 6$ concentration of $20 \mu{\mathrm{M} .{ }^{43}}$ Ce6-encapsulated micelles were dialyzed against deionized water for $48 \mathrm{~h}$ in dark conditions using a dialysis bag (MWCO 8000 to 14000 ) to remove the organic solvent and free Ce6. A549 cells $\left(1 \times 10^{6}\right.$ cells in $300 \mu \mathrm{L}$ PBS $)$ were injected into the mice through left subcutaneous injection. When the tumor volume reached $100 \mathrm{~mm}^{3}$ (about three weeks later), the mice were intravenously injected through the tail vein with Ce6encapsulated micelles fabricated by dialysis (CMD); Ce6encapsulated micelles fabricated by microfluidics (CMM); and Ce6-encapsulated targeting micelles fabricated by microfluidics (CTMM), respectively $(n=5)$. Following anesthetization, the mice were imaged pre-injection and 2, 4, 6, and $9 \mathrm{~h}$ after injection of the micelles. At $9 \mathrm{~h}$ after injection, further observation of micelles in tumors and other key organs (the liver, kidneys, spleen, heart, and lungs) was performed.

\subsection{Diffusion and penetration behavior of micelles in tumor tissue}

In order to study the permeation and maintenance effects of different micelles in tumors, fluorescent slices from different treated mice were acquired. The micelles were injected into tumor-bearing nude mice through the tail vein, and each mouse was injected with an equivalent dose of $10 \mathrm{mg} \mathrm{kg}^{-1}$ of Ce6. After 9 hours, the mice were sacrificed and the tumors were removed to be made into slices. Each tumor was sliced into numerous 
frozen sections from top to bottom. All fluorescent sections were observed under a confocal laser scanning microscope to study the diffusion and penetration behavior of the micelles into the tumors.

\subsection{Antitumor efficacy of micelles}

$100 \mu \mathrm{L}$ of a single-cell suspension containing $1 \times 10^{6}$ A549 cells was introduced subcutaneously under the right armpit of Balb/c nude mice. When the tumor size reached $100 \mathrm{~mm}^{3}$, the nude mice were randomly divided into five groups $(n=5)$ : control group (saline solution); the DTXL group (10 $\mathrm{mg} \mathrm{kg}^{-1}$ of free docetaxel); DMD group (10 $\mathrm{mg} \mathrm{kg}^{-1}$ of free docetaxel); DMM group (10 $\mathrm{mg} \mathrm{kg}^{-1}$ of free docetaxel); and DTMM group (10 mg $\mathrm{kg}^{-1}$ of free docetaxel). The mice were injected with the treatment drug through the tail vein twice a week for four weeks. During the treatment, the tumor volumes and the weights of the nude mice were examined regularly (every four days). After the $32^{\text {nd }}$ day of treatment, the mice were euthanized and pictures of the tumors were taken. The tumor volumes were calculated as $V$ $=a \times b^{2} / 2$, where $a$ and $b$ are the length and width of the tumor, respectively. Histological examination of tumors from different treatments was performed with hematoxylin and eosin (H\&E) staining to observe the status of cancer cells after the different treatments.

\subsection{Western blotting}

Western blotting was performed to analyze the expression level of heat shock protein 70 (HSP70) in tumor tissues after the different treatments. Briefly, tumors removed from the nude mice in the previous antitumor efficiency experiment were cut into small pieces and lysed in Radio Immunoprecipitation Assay (RIPA) buffer with a proteinase inhibitor. Then, these compounds were ground in a homogenizer until the tumor fragments disappeared in the lysate, followed by 5 minutes of centrifugation to obtain the supernatant. The protein concentrations were measured using the BCA Protein Concentration Assay Kit (Beyotime Biotechnology, Shanghai, China). After normalization, equal amounts of proteins were fractionated using $10 \%$ SDS-polyacrylamide gels and transferred to polyvinyllidene fluoride (PVDF) membranes. Then, these membranes were washed with Tris-Buffered Saline and Tween 20 (TBST) at room temperature for $5 \mathrm{~min}$. After being blocked in $5 \%$ BSA at room temperature for $2 \mathrm{~h}$, the membranes were washed three times with TBST and incubated with the appropriate primary anti-Hsp70 antibody at dilution concentrations of $1: 1000$ in TBST-5\% BSA for $12 \mathrm{~h}$ at $4{ }^{\circ} \mathrm{C}$. After washing with TBST, the membranes were incubated with goat anti-mouse IgG-horseradish peroxidase conjugates (1:2000 dilution) at room temperature for $2 \mathrm{~h}$. Finally, the immunoblots were visualized using an enhanced chemiluminescence (ECL) advanced Western blot detection kit (Merck Millipore, Billerica, MA, USA).

\subsection{Histological examination}

The potential for in vivo toxicity has always been of great concern in the development of nanodrugs. To study potential changes in the organ morphology of tumor-bearing mice, histological examination was conducted after the antitumor efficacy experiment. The main organs (heart, liver, spleen, lungs, and kidneys) of the treated mice were collected and fixed in $10 \%$ formalin solution at $4{ }^{\circ} \mathrm{C}$. The tissues were then embedded in paraffin, sliced 5 to 8 microns thick, and placed onto glass slides. Subsequently, these glass slides were stained with hematoxylin and eosin (H\&E) and were imaged with fluorescence microscopy (Nikon, Tokyo, Japan).

\subsection{Statistical analyses}

Experimental data are expressed as the mean \pm standard deviation (SD). Statistics were analyzed using SPSS 13.0 software (SPSS Inc., Chicago, IL, USA). Group differences were determined with one-way analysis of variance (ANOVA). A $P$ value of less than 0.05 was considered to be statistically significant.

\section{Results and discussion}

\subsection{Micelle formulation and characterization}

Polymeric micelles are usually formed through the selfassembly of amphiphilic copolymers in aqueous media at the critical micelle concentration (CMC). ${ }^{44}$ This drug delivery system comprises a spherical core-shell structure, which contains a hydrophobic inner core that can be used to solubilize or entrap hydrophobic drugs and a hydrophilic outer shell that can protect drugs from the surrounding aqueous environment and provide particles with steric stability. ${ }^{45-47}$ In this study, poly(lactide-co-glycolic acid)- $b$-poly(ethylene-co-glycol)maleimide (PLGA-PEG-Mal; LA : GA $50: 50 M_{\mathrm{w}}$ : $30000: 5000$ ) was applied due to its superior water solubility and biodegradability. In the present study, the micelles prepared by microfluidics were homogeneous, with a spherical morphology (Fig. 1). The average sizes of DMD, DMM and DTMM were $145 \pm$ $1 \mathrm{~nm}(\mathrm{PDI}=0.390), 72 \pm 1 \mathrm{~nm}(\mathrm{PDI}=0.072)$, and $78 \pm 1 \mathrm{~nm}$ $(\mathrm{PDI}=0.064)$, respectively. The particle sizes and size distributions of these micelles remained stable over time (ESI Table $3 \dagger)$. Furthermore, a recent study by P. Rafiei et al. showed that average size of micelles using a modified emulsification solvent evaporation technique was $123.6 \pm 9.5 \mathrm{~nm},{ }^{48}$ which is noticeably larger than that of the micelles based on microfluidics. These results indicate significant advantages of microfluidics for forming small, homogeneous particles. Encouragingly, the drug loading efficiency of DMM was found to be three-fold higher than that of DMD (11.18\% vs. $4.50 \%)$ (Table 1). During the bulk preparation, the fluidic control is deficient, which causes the copolymers to aggregate rapidly; ${ }^{49}$ therefore, the drugs will not be loaded efficiently and the drug loading efficiency is relatively low. For microfluidics, because of the wellcontrolled synthesis process, the mixing timescale is shorter than the characteristic timescale; therefore, particle selfassembly occurs primarily when the solvent change is complete, and more drugs can be loaded. ${ }^{18}$ The zeta potential (in PBS medium, pH 7.4) of these micelles was neutral (Fig. 1C), confirming their non-ionic status. 
A

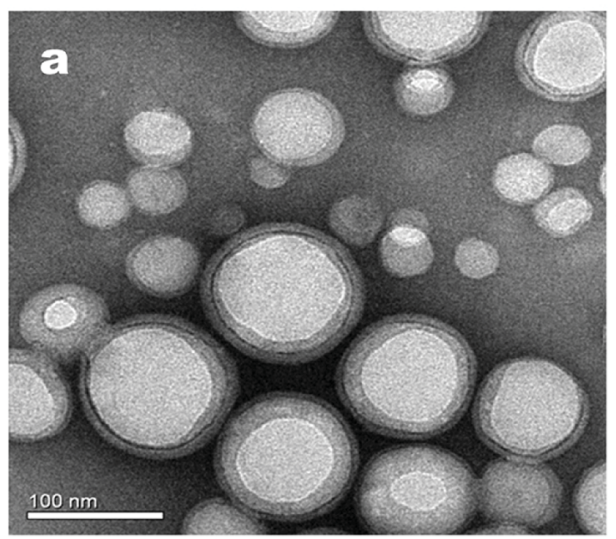

B

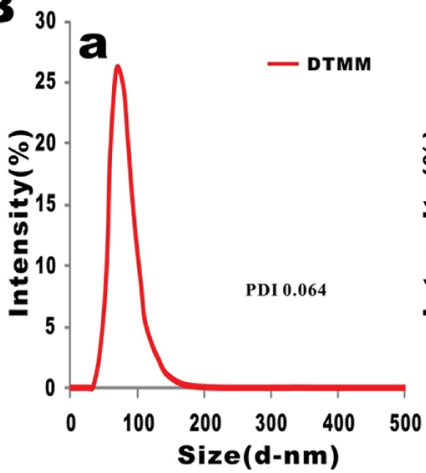

C

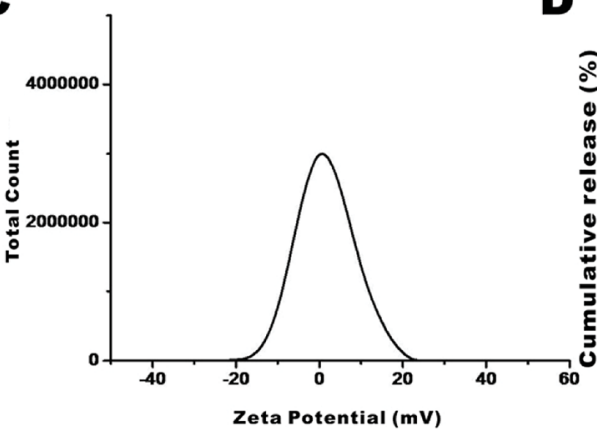

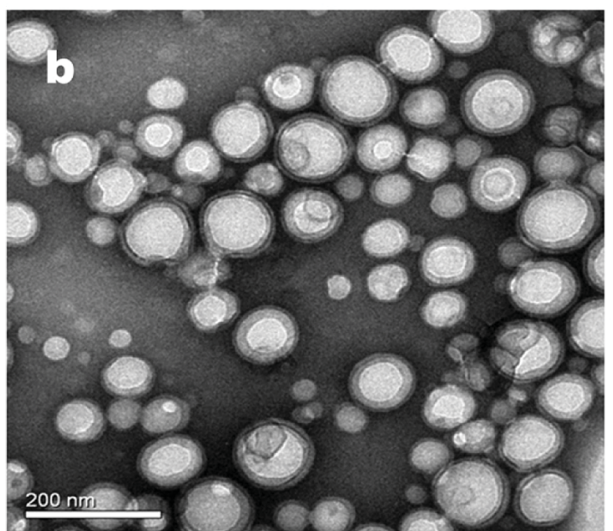
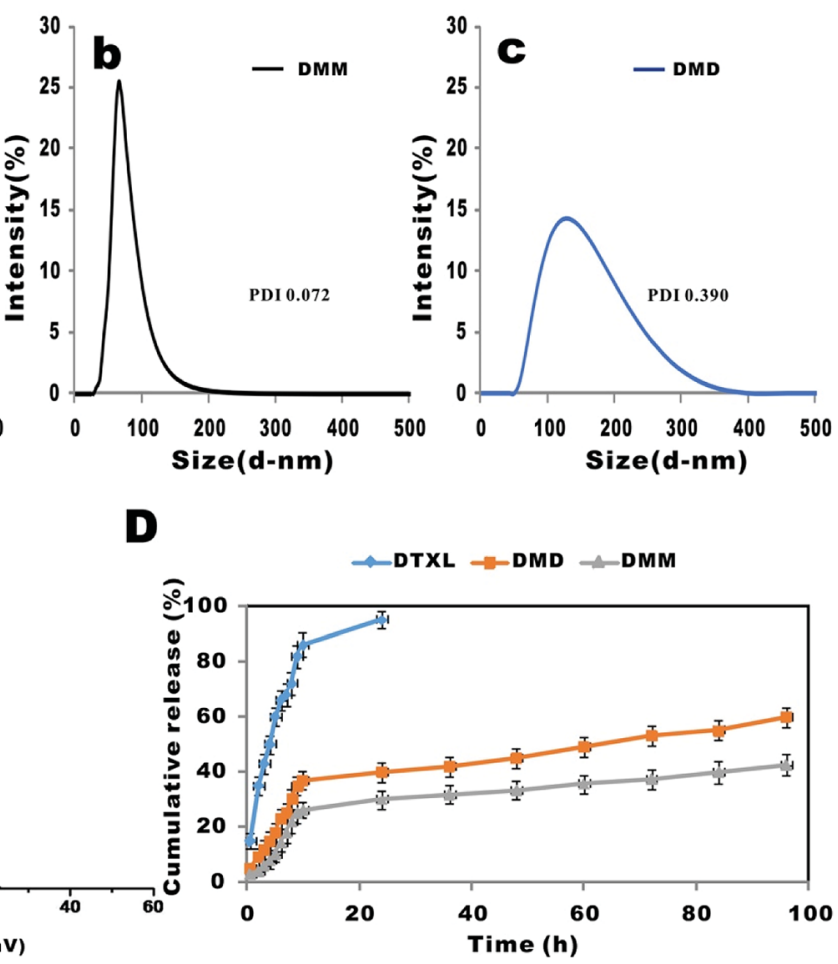

Fig. 1 Physicochemical characterization of docetaxel-loaded micelles. (A) TEM images of drug-loaded micelles prepared by microfluidics; the samples were stained with $1 \%$ phosphotungstic acid. (a) Scale bar $=100 \mathrm{~nm}$. (b) Scale bar $=200 \mathrm{~nm}$. (B) Size distributions and polydispersities of different micelles measured by DLS analysis: (a) DTMM, (b) DMM, (c) DMD. (C) Zeta potential of the micelles from three different groups. (D) Docetaxel release curves determined by dialysis in PBS release medium $\left(37^{\circ} \mathrm{C}, \mathrm{pH} 7.4\right)$. Each data point represents the mean $\pm \mathrm{SD}$ of three tests.

Table 1 Drug loading and drug encapsulation of different micelles. The data are presented as the mean \pm SD

\begin{tabular}{lrl}
\hline Formulation & \multicolumn{1}{c}{ DL (\%) } & \multicolumn{1}{l}{ EE (\%) } \\
\hline DMD & $4.50 \pm 1.25$ & $45.16 \pm 2.20$ \\
DMM & $11.12 \pm 1.17$ & $66.54 \pm 2.50$ \\
DTMM & $10.85 \pm 1.54$ & $66.12 \pm 1.90$
\end{tabular}

\subsection{In vitro release of docetaxel}

The in vitro drug release curves of free DTXL and docetaxelloaded micelles are shown in Fig. 1D. In the first $10 \mathrm{~h},>80 \%$ of docetaxel was burst-released from the DTXL solution. When the majority of the docetaxel was released, the internal osmotic pressure from the dialysis bag decreased gradually and the external osmotic pressure from the dialysis medium increased gradually. When the equilibrium osmotic pressure was reached, docetaxel would not release from free DTXL. Thus, although $>95 \%$ of the docetaxel was released within $24 \mathrm{~h}$, complete release could not achieved..$^{50}$ Docetaxel was released much more slowly from DMD than from DTXL solution, without burst release; the release percentage of DMD was $46.12 \% \pm 3.01 \%$ at the $48 \mathrm{~h}$ point, which demonstrated the solubility and delayed release characteristics of the micelles. For DMM, the release percentage was $33.03 \% \pm 3.06 \%$ at $48 \mathrm{~h}$, which is a slower rate compared with DMD. This release 


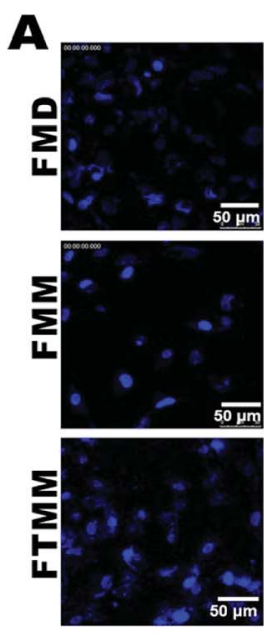

B
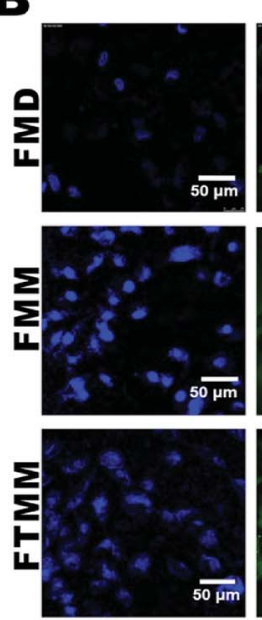

c

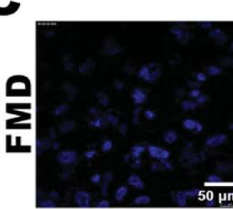

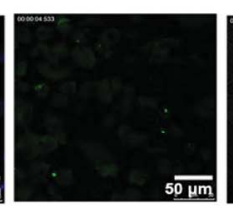
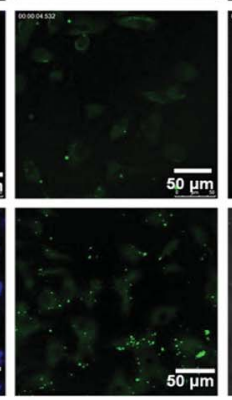

$2 \mathrm{~h}$
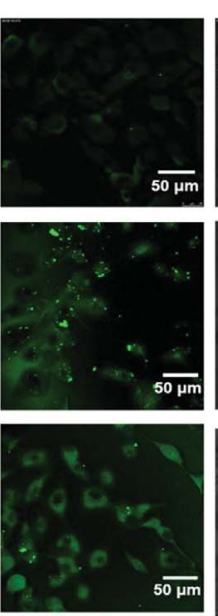

4
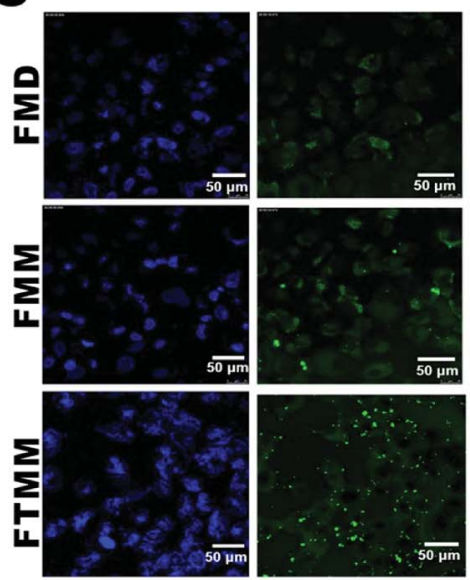
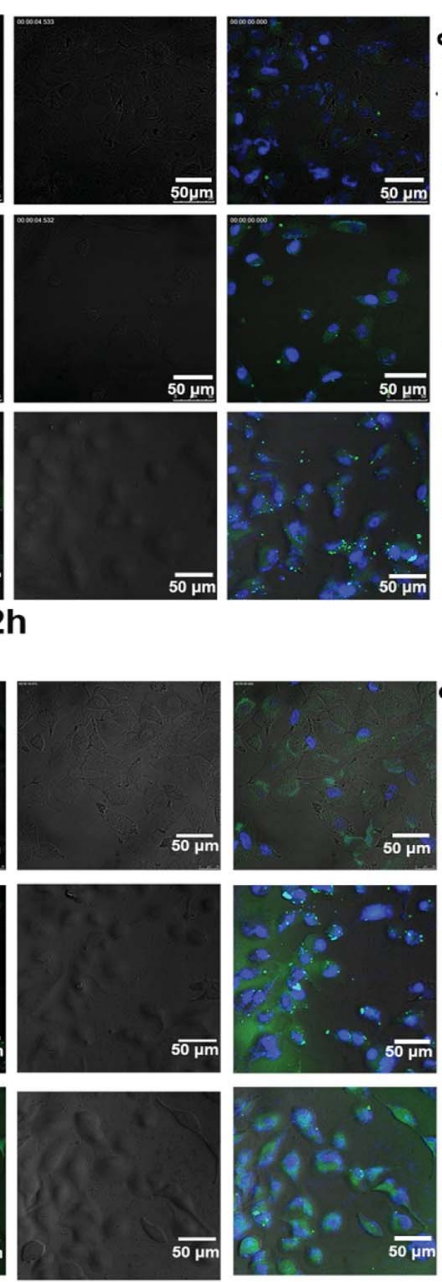

4h

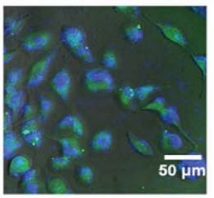

$50 \mu$
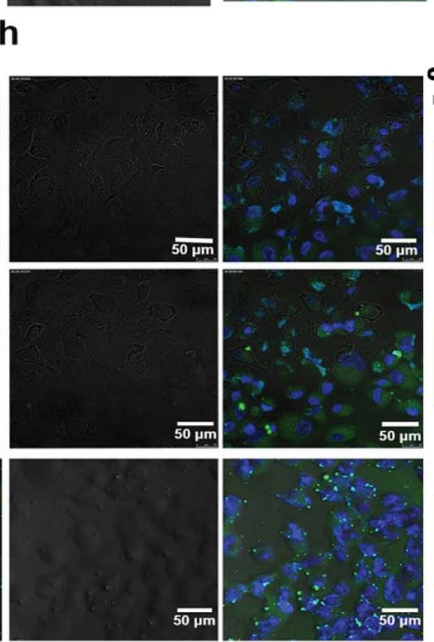

$\overline{50 \mu \mathrm{m}}$

\section{Cell uptake (\%)}

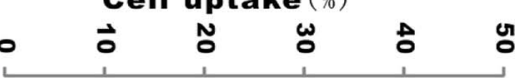

Cell uptake (\%)

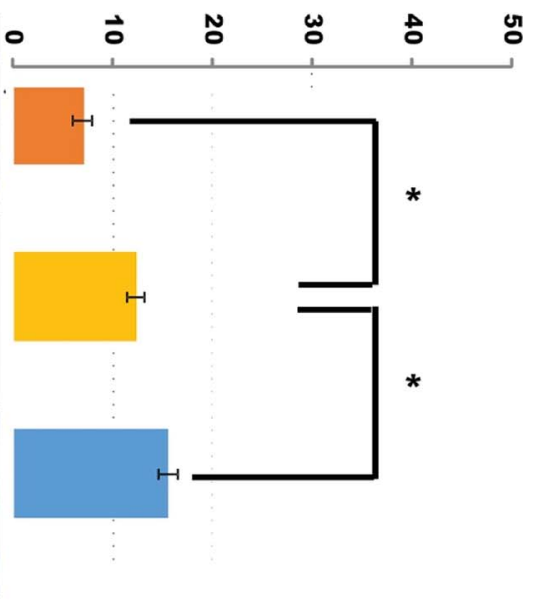

Cell uptake (\%)
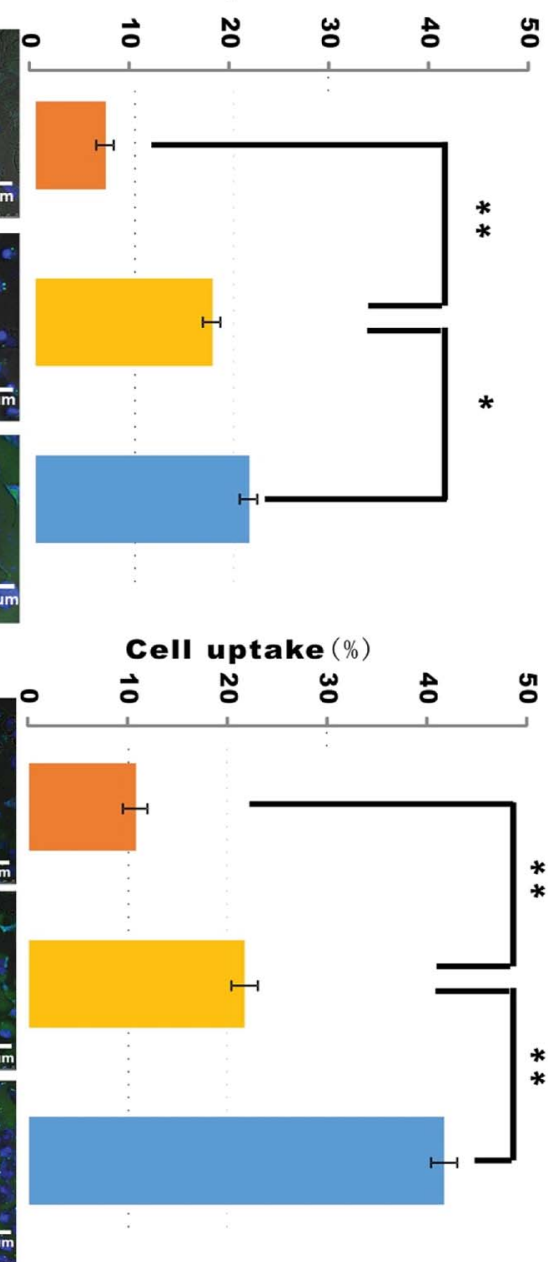

Fig. 2 Confocal images of A549 (A-C) and 3LL cells (D-F) co-incubated with micelles for certain times. In the image sequence, the first and second images present the fluorescence of blue DAPI and green FITC, respectively; the third image displays the cellular outline; the fourth overlays the former three images. (A) Confocal images and flow cytometry assay of A549 cells co-incubated with different micelles for 2 h. (B) Confocal images and flow cytometry assay of A549 cells co-incubated with micelles for $4 \mathrm{~h}$. (C) Confocal images and flow cytometry assay of A549 cells co-incubated with micelles for $6 \mathrm{~h}$. (D) Confocal images and flow cytometry assay of $3 \mathrm{LL}$ cells co-incubated with different micelles for $2 \mathrm{~h}$. (E) Confocal images and flow cytometry assay of $3 \mathrm{LL}$ cells co-incubated with micelles for $4 \mathrm{~h}$. (F) Confocal images and flow cytometry assay of $3 \mathrm{LL}$ cells co-incubated with micelles for $6 \mathrm{~h}$. The data are presented as the mean $\pm \mathrm{SD}$. $* P<0.05, * * P<0.01$. 

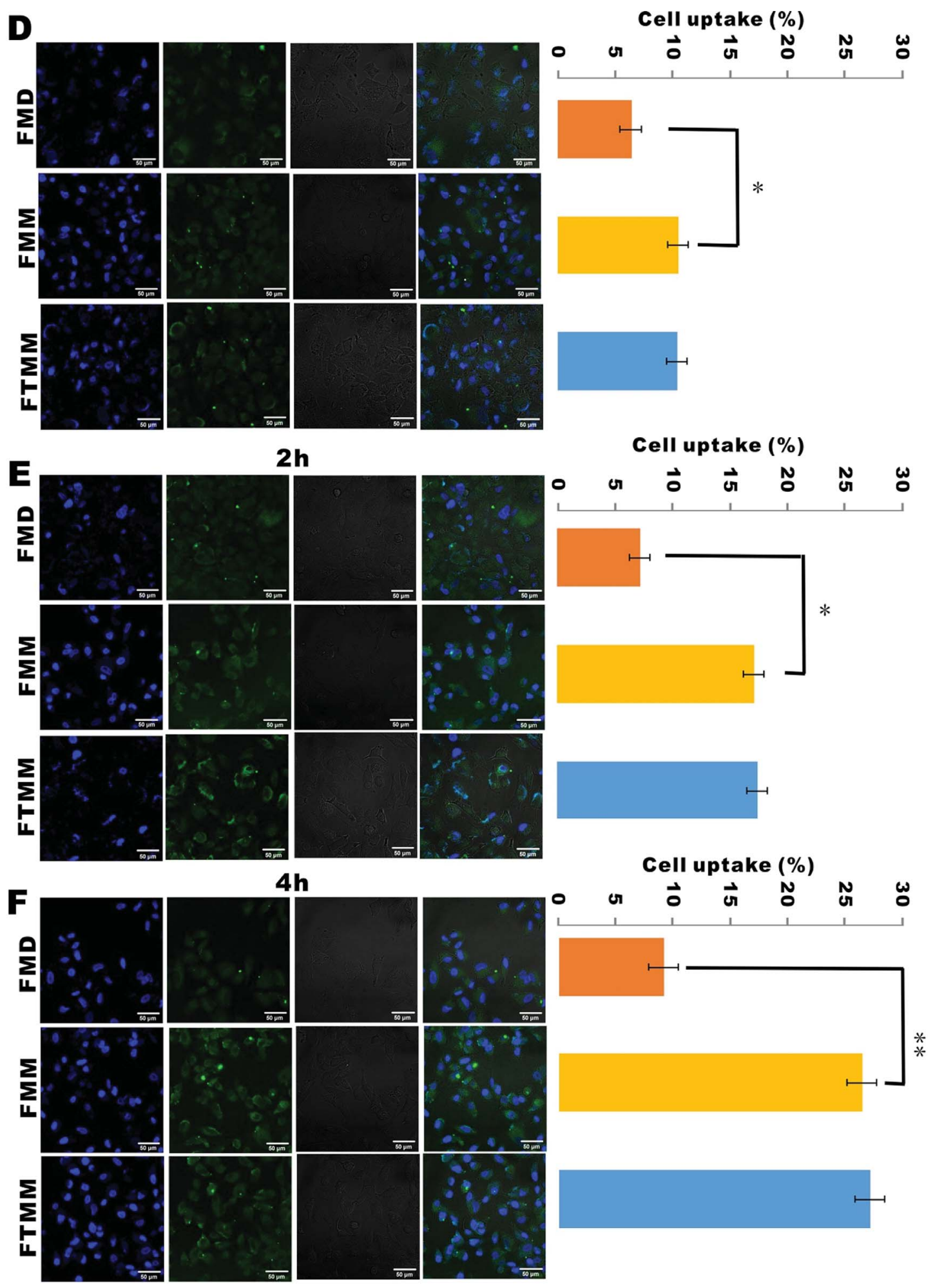

$6 h$

Fig. 2 (contd.)

difference is related to the well-controlled and homogeneous mixing in microfluidics, ${ }^{\mathbf{1 8}}$ which produced micelles with uniform drug distribution. Meanwhile, fluidic control of the dialysis preparation is more difficult; therefore, the micelle particles may have drug-rich domains at or near the particle surface, ${ }^{51,52}$ and more drugs adsorbed near the surface leads to faster release from the micelle particles. 


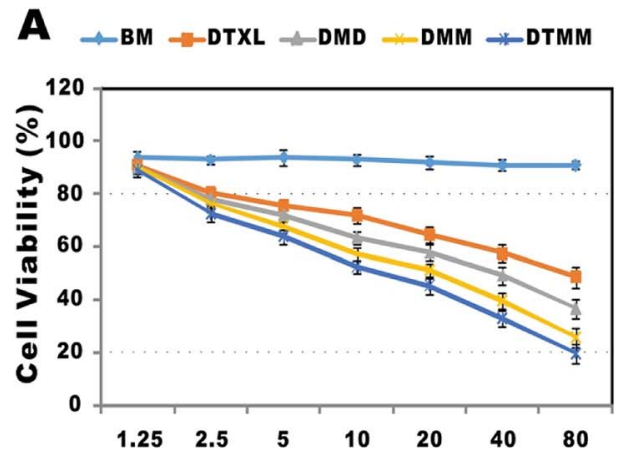

Docetaxel Concentration ( $\mathrm{nmol} / \mathrm{mL}$ )

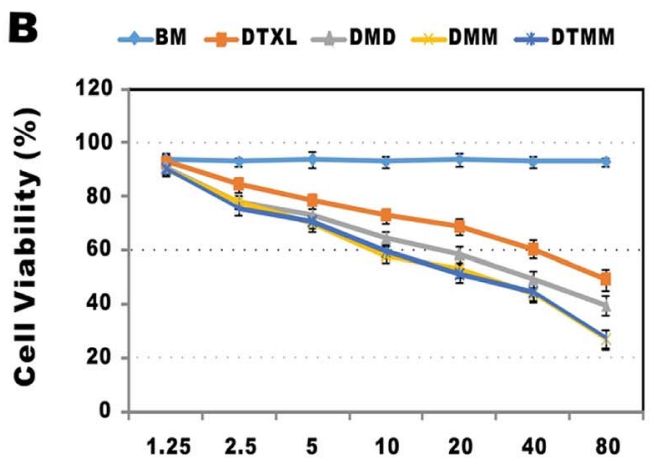

Docetaxel Concentration ( $\mathrm{nmol} / \mathrm{mL}$ )

Fig. 3 In vitro cytotoxicity of DTXL and different micelles against A549 (A) and 3LL cells (B) (mean \pm SD, $n=3$ ).

\subsection{In vitro cellular uptake}

Arginine-glycine-aspartate (RGD), a minor polypeptide consisting of a triamino acid sequence, is an important ligand that specifically binds to $\alpha v \beta 3 .^{53,54}$ Integrin $\alpha v \beta 3$ is specifically overexpressed in numerous cancer cells and tumor endothelial cells; however, it is not expressed or rarely expressed in non- tumor cells. ${ }^{55}$ Therefore, the RGD- $\alpha \mathrm{v} \beta 3$ motif is widely studied in cancer diagnosis and treatment, ${ }^{56-60}$ including NSCLC. ${ }^{61}$ Many studies have proved that $\alpha \mathrm{v} \beta 3$ is highly expressed in A549 cells. $^{62-65} \mathrm{C}$. Khemtong et al. also designed superparamagnetic polymeric micelles encoded with RGD to target $\alpha \mathrm{v} \beta 3$-expressing A549 cells. $^{66}$ Additionally, the 3LL cell line, which does not

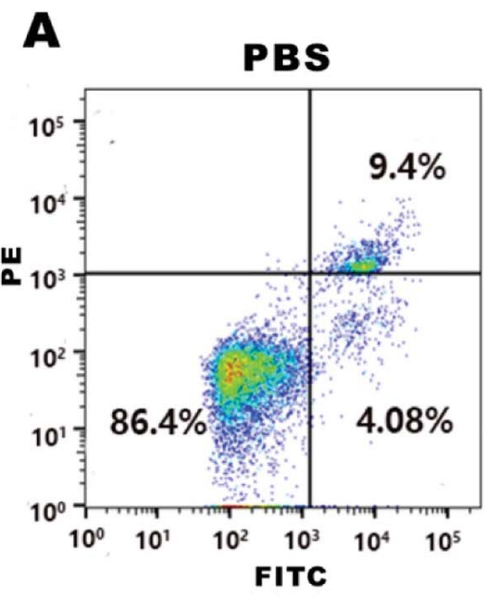

\section{B}
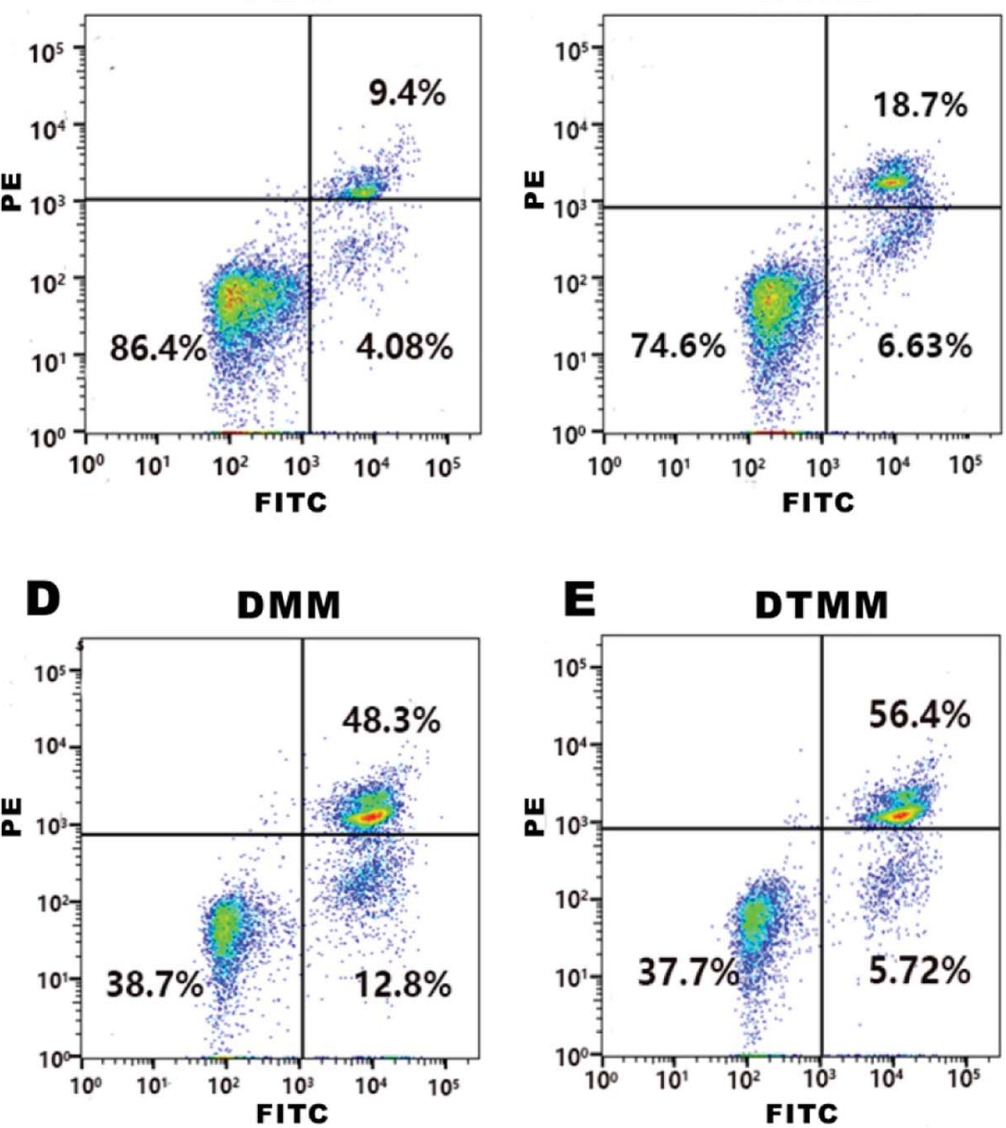

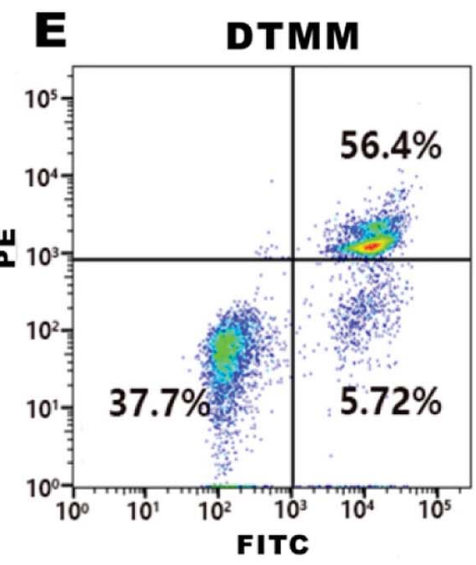

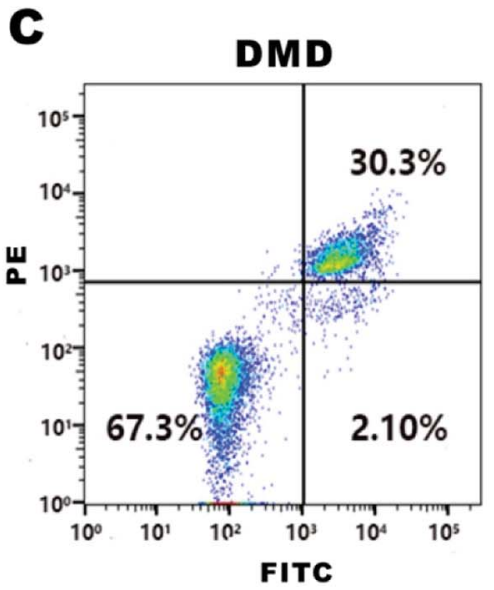

$\mathbf{F}$

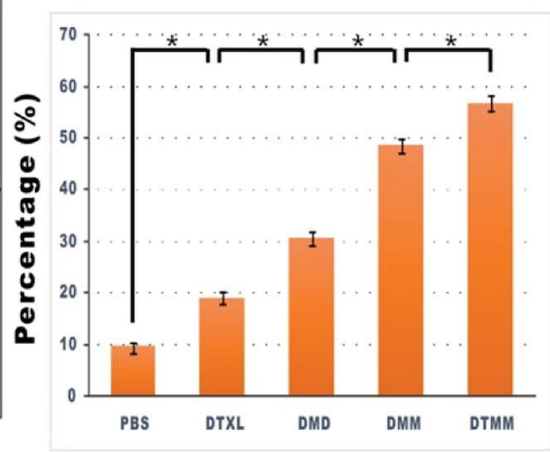

Fig. 4 Flow cytometry assays detecting apoptosis of A549 cells. Apoptosis rates of (A) PBS treatment, (B) DTXL treatment, (C) DMD treatment, (D) DMM treatment, (E) DTMM treatment; (F) histogram of the apoptosis assays. Each data point represents the mean $\pm S D$ of three tests. ${ }^{*} P<0.05$, $* * P<0.01$. 

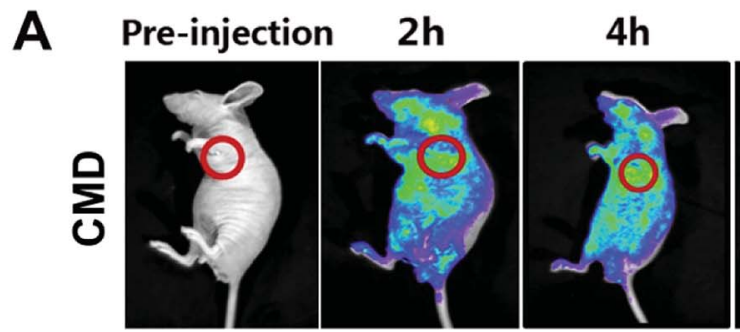

4h
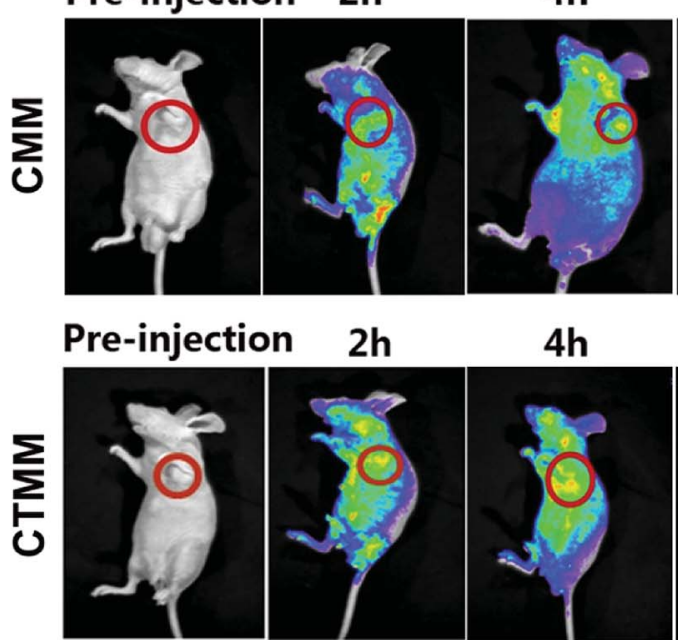

$2 \mathrm{~h}$

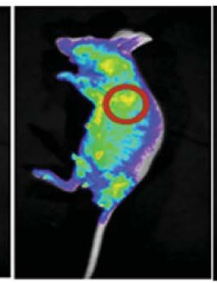

4h
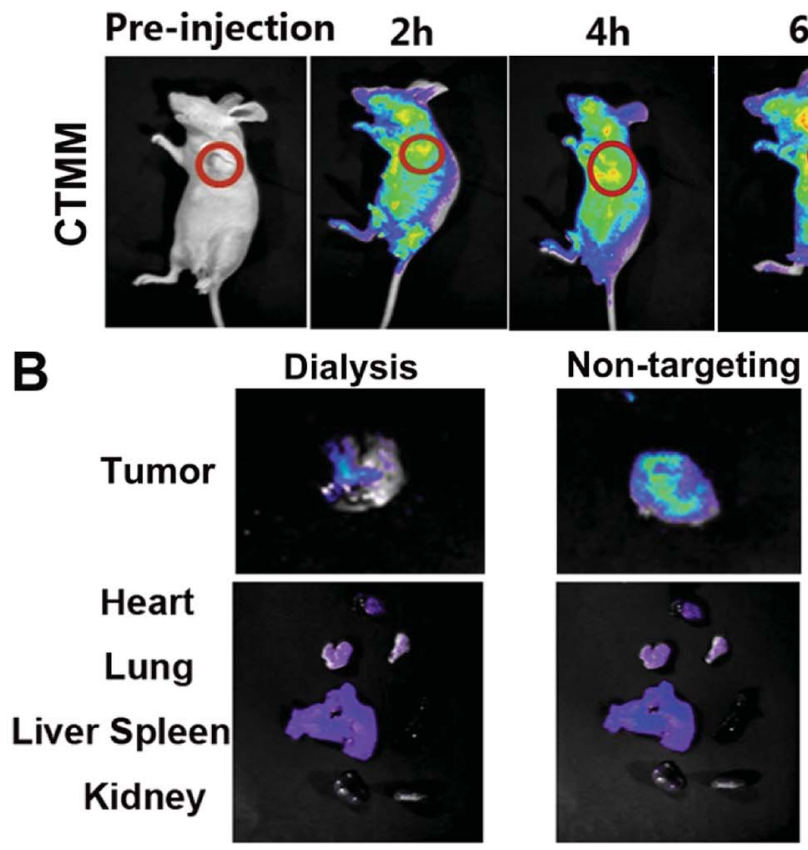

$6 \mathrm{~h}$

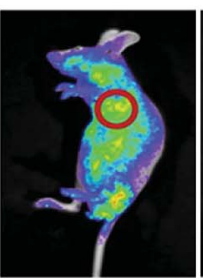

$6 \mathrm{~h}$

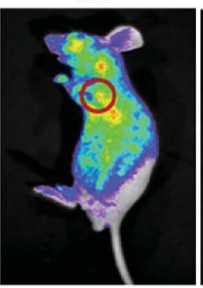

$6 \mathrm{~h}$

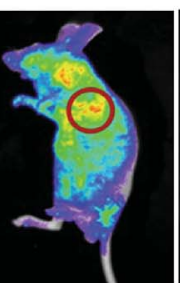

B
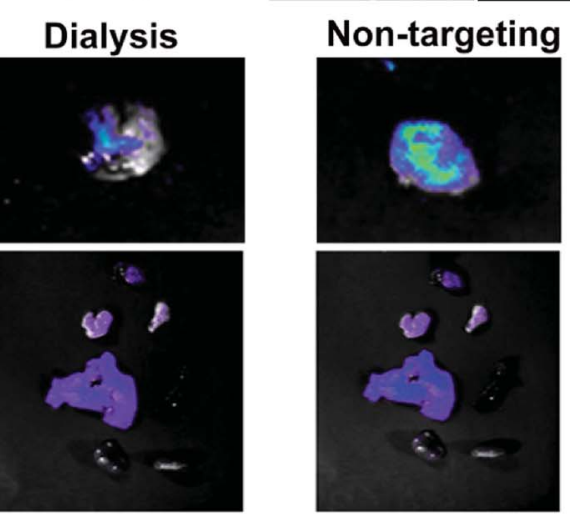

$9 \mathrm{~h}$

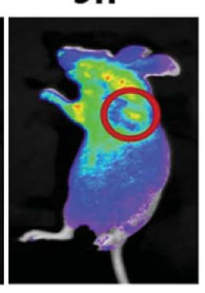

$9 \mathrm{~h}$

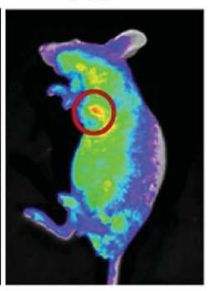

$9 \mathrm{~h}$

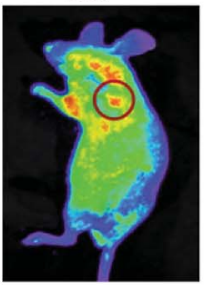

Targeting
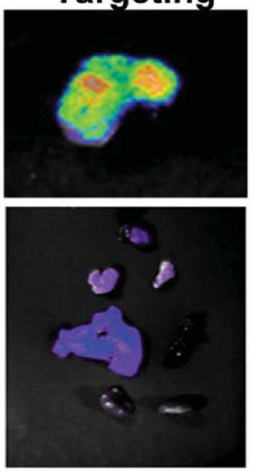

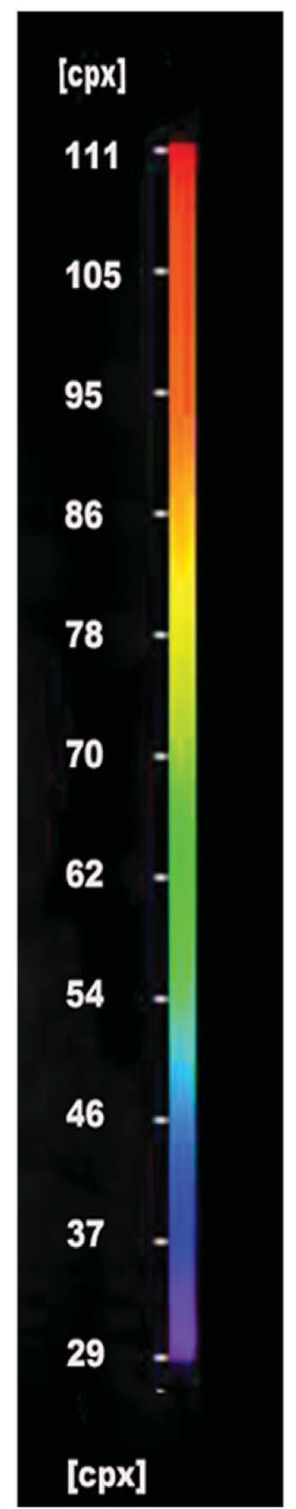

Fig. 5 Fluorescence images of tumor-bearing nude mice (A) and their major organs (B) at different time points after intravenous injection of Ce6 encapsulated micelles.

express $\alpha \mathrm{v} \beta 3$ integrin, was applied for in vitro studies to reflect the targeting effects of RGD on A549 cells.

The in vitro cellular uptake of FITC-probed micelles in A549 and 3LL cells is shown in Fig. 2A and B. After excitation, the FITC dye in the cells showed green fluorescence, while the DAPI in the cell nuclei showed blue fluorescence. The green fluorescence intensities of FMM were significantly stronger than those of FMD at 3 time points. Meanwhile, the fluorescence intensities of FTMD were greater than those of FMM. The cellular uptake efficiency was examined by flow cytometry (ESI Fig. $4 \dagger$ ), and the results were consistent with the fluorescence images. Because micelles can be uptaken into cells through endocytosis, the size dimensions and size homogeneity of the micelle particles are considered to be key characteristics to determine the cell uptake efficiency. ${ }^{67}$ Compared with particles of FMD, cells prefer smaller and homogeneous particles from FMM. The more enhanced uptake of FTMM into cells can be attributed to the targeting effects of cyclic RGDfK in addition to the small particle size and homogeneity. In contrast, the fluorescence intensity of FTMM was as strong as that of FMM due to the absence of $\alpha v \beta 3$ in $3 \mathrm{LL},{ }^{41}$ and the same result was obtained using the flow cytometry assay.

\subsection{Cytotoxicity studies}

The MTT assay was performed to investigate the in vitro cytotoxic activities of drug-loaded micelles against A549 and 3LL cells. As shown in Fig. 3A, the blank micelles had almost no toxicity to A549 cells, demonstrating the biological safety of PLGA-PEG-Mal. The $\mathrm{IC}_{50}$ of DMM was lower than that of DMD 


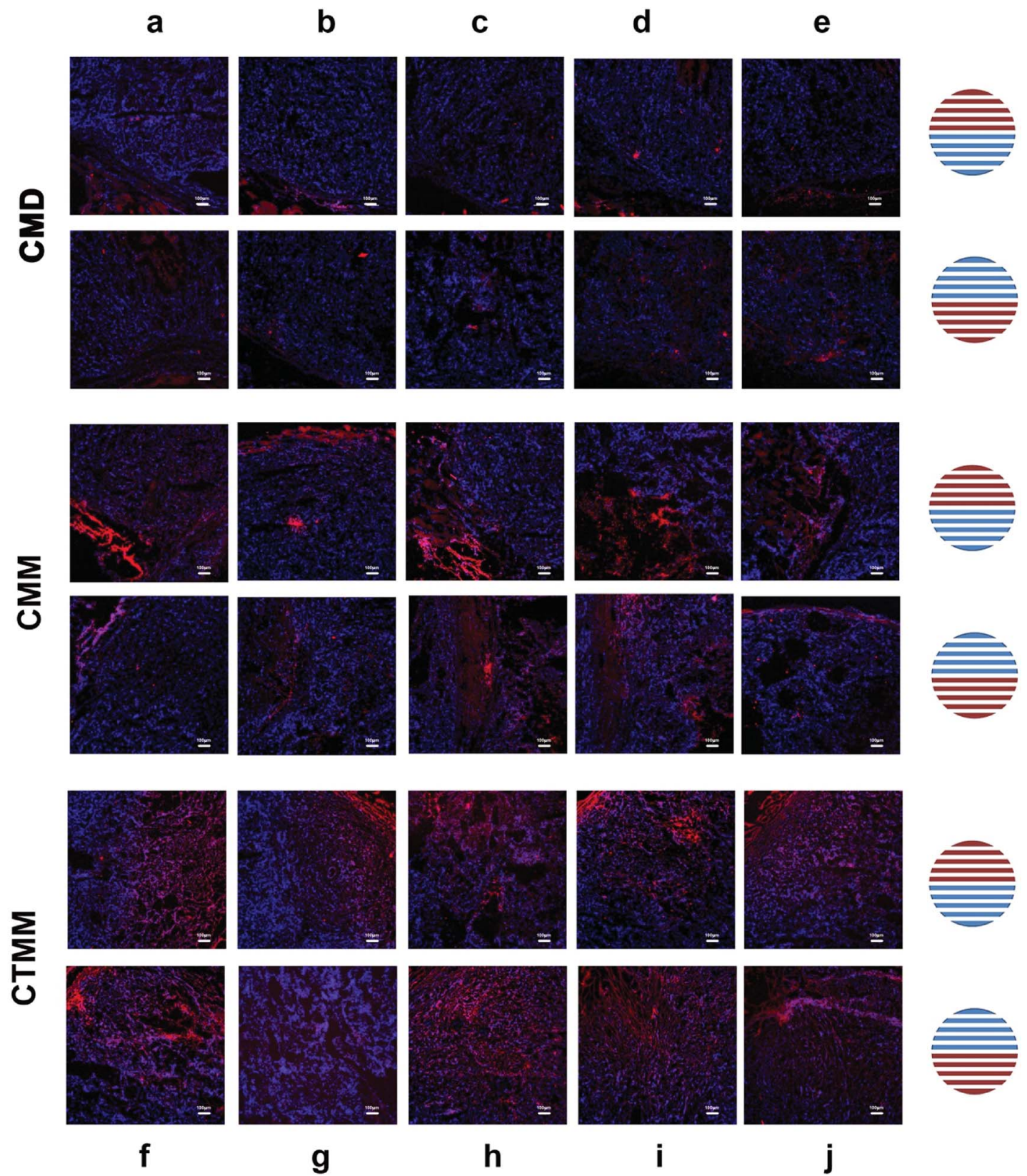

Fig. 6 Fluorescence images of distribution and permeation activity into tumors of Ce6-encapsulated micelles. Ten images from each tumor are placed from left-top to bottom-right from (a to j) in the figure. In each image, the Ce6 dye shows red fluorescence while the DAPI in the cell nuclei shows blue fluorescence.

(26.0 $\mu \mathrm{M}$ vs. $43.5 \mu \mathrm{M}, P<0.05)$, indicating that DMM entered into cells more efficiently and released drugs continuously. ${ }^{67}$ The $\mathrm{IC}_{50}$ of DTMM was slightly lower than that of DMM $(19.3$ $\mu \mathrm{M} v$ s. $26.0 \mu \mathrm{M}, P<0.05)$, indicating the targeting effect of cyclic RGDfk. ${ }^{68,69}$ Meanwhile, in the 3LL cell line, the $\mathrm{IC}_{50}$ of DMM was also smaller than that of DMD $(26.7 \mu \mathrm{M}$ vs. $44.1 \mu \mathrm{M}, P<0.05)$ but was nearly identical to that of DTMM $(26.7 \mu \mathrm{M} v s .26 .3 \mu \mathrm{M}, P$ $<0.05$ ) (Fig. 3B), indicating that the targeting effect of RGDfK was greatly decreased. This result indicates that $3 \mathrm{LL}$ cells do not express $\alpha \mathrm{v} \beta 3$ integrin.

\subsection{Cell apoptosis detection}

The apoptotic rates of A549 cells were analyzed via flow cytometry. The apoptosis rate of DMD was approximately 2-fold higher than that of DTXL $(30.3 \%$ vs. $18.7 \%, P<0.05)$. The apoptosis rate of DMM was higher than that of DMD $(48.3 \%$ vs. $30.3 \%, P<0.05)$. Treatment with DTMM increased the apoptotic cell proportion to $56.4 \%$ (Fig. 4 ). These results indicate that the micelles based on microfluidics induced intense apoptosis in A549 cells. 


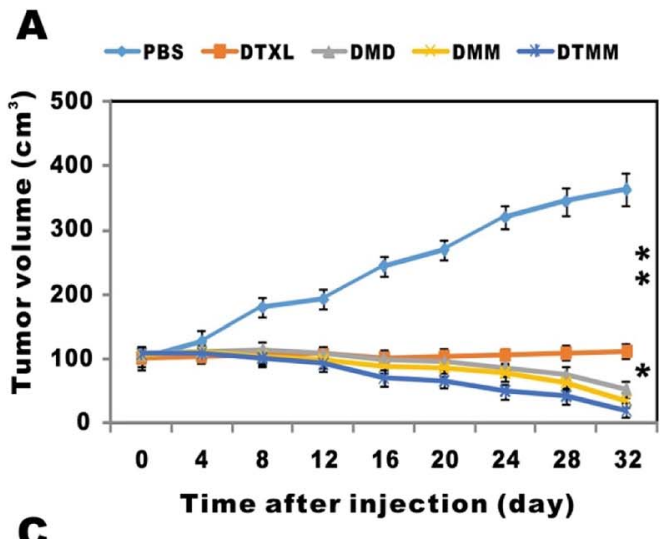

\section{B}
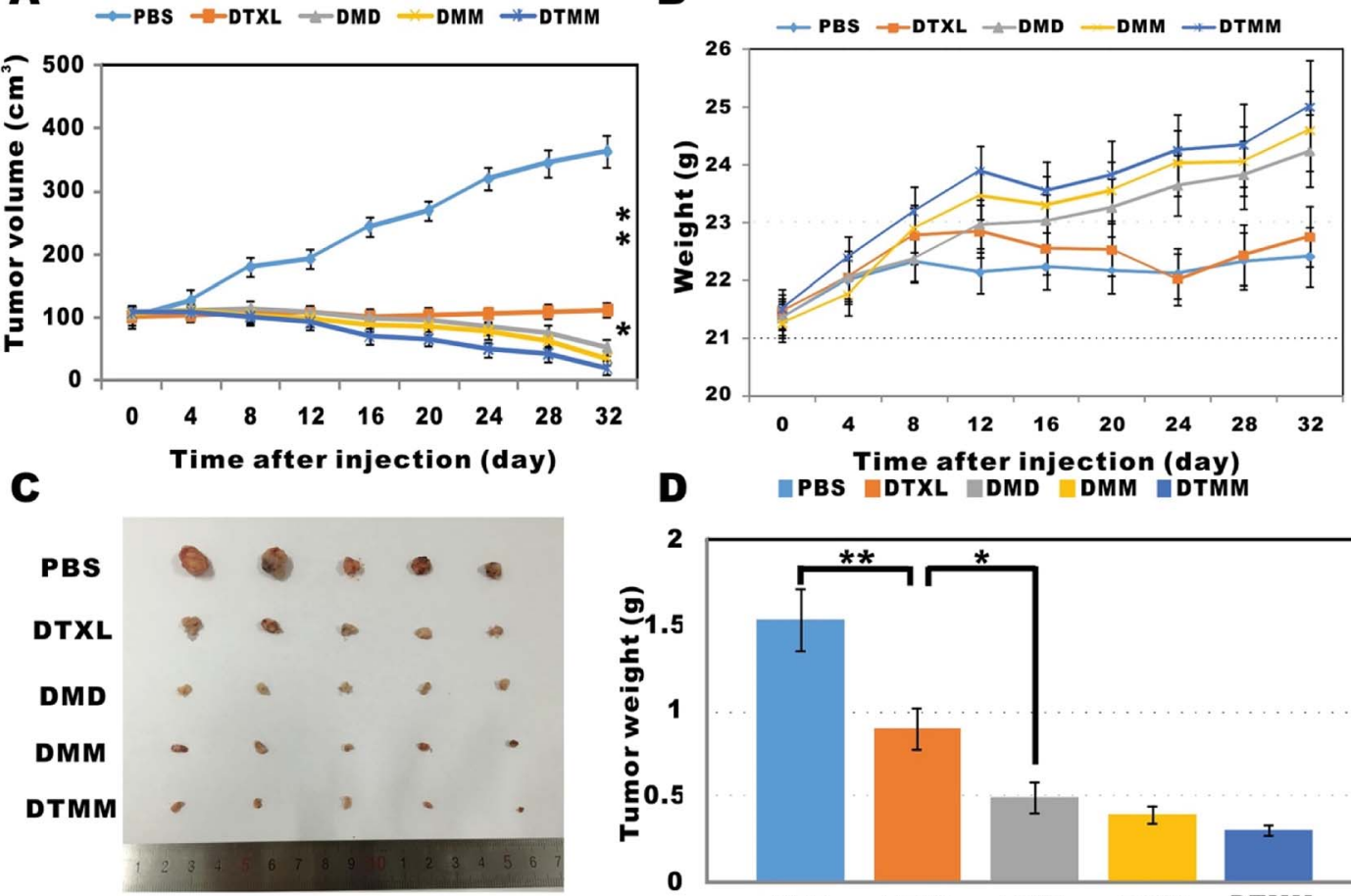

E

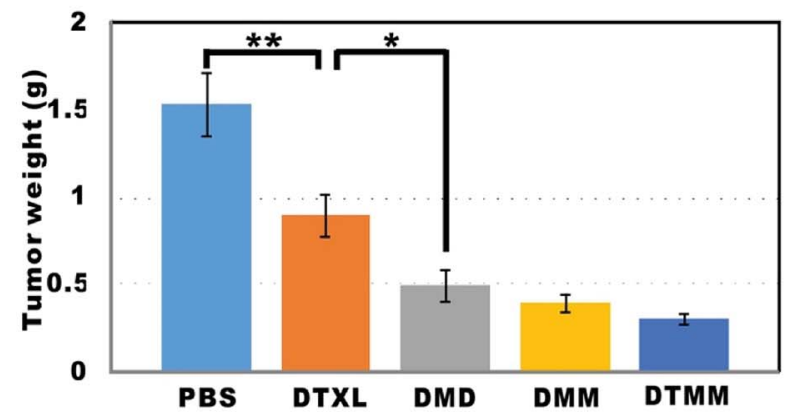

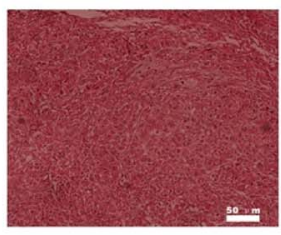

PBS

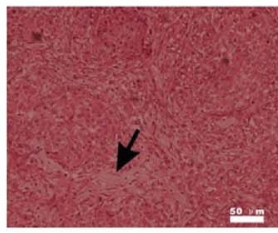

DTXL

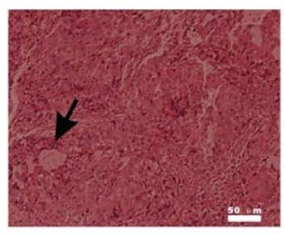

DMD

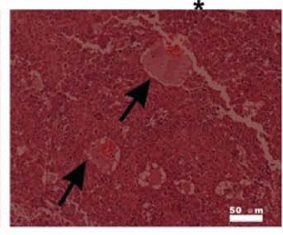

DMM

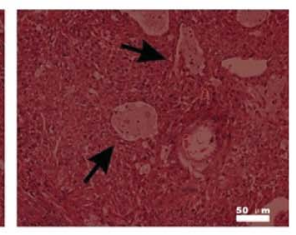

DTMM

Fig. 7 In vivo antitumor study of micelles in A549 tumor-bearing nude mice. (A) Graph of tumor volume changes during the treatment. (B) Graph of body weight changes during the treatment. (C) Photograph of tumors from five groups on the $32^{\text {nd }}$ day of drug administration. (D) Histogram of tumor weights from different groups on the $32^{\text {nd }}$ day of drug administration. (E) Histological assay of tumors with H\&E staining; partial or bulk necrotic cancer cells are indicated by arrowheads. The results are presented as the mean $\pm \mathrm{SD}$. $* P<0.05, * * P<0.01$.

\subsection{In vivo imaging of different micelles}

In vivo imaging was performed to investigate the distribution of the Ce6-encapsulated micelles in tumor-bearing nude mice. As shown in Fig. 8A, the Ce6-encapsulated micelles accumulated in the liver at $9 \mathrm{~h}$, indicating that the micelles were not rapidly cleared by the mononuclear phagocyte system. ${ }^{70}$ As shown in Fig. 5B, the fluorescence intensity in tumor tissue steadily increased with time. Among the differently treated mice, the fluorescence intensity of CMM was stronger than that of CMD, and CTMM showed more intensive fluorescence than CMM. There were no significant differences in the fluorescence intensities of the major organs between groups (Fig. 5B). Moreover, the penetration and maintenance effect of Ce6encapsulated micelles into tumors was studied by fluorescent slices under a confocal microscope (Fig. 6). For each tumor treated with micelles, 10 pathological slices were obtained from upper-left to bottom-right, which are shown as images (a-j) in Fig. 6 . The $\mathrm{Ce} 6$ dye in the cells showed red fluorescence, while the DAPI in the cell nuclei showed blue fluorescence. CMM possessed enhanced penetration and maintenance effects in tumor tissue compared with CMD, while CTMM permeated more and deeper than CMM. This result was consistent with the in vivo imaging. Therefore, micelles prepared by microfluidics had powerful accumulation and greater permeation effects into tumors. Furthermore, RGDfK-labeled micelles showed stronger accumulation because of targeting effects.

\subsection{Antitumor activity in tumor-bearing nude mice}

The in vivo antitumor effects of micelles were studied in tumorbearing athymic nude mice. The tumor volume time curve and weight analysis are presented in Fig. 7. The average tumor inhibition rates of DMM and DTMM were higher than those of DTXL $(P<0.05)$ and DMD (Fig. 7A), indicating that the micelles prepared by microfluidics were effective in tumor inhibition and regression. In the micelles-treated mice, the body weights of the DMM and DMD groups were $24.80 \pm 0.81 \mathrm{~g}$ and $24.20 \pm$ $0.63 \mathrm{~g}$ on the $32^{\text {nd }}$ day, respectively, whereas that of the control group was $22.60 \pm 0.69 \mathrm{~g}$; this indicates that the micelles had almost no toxicity in vivo. Moreover, the growth rates of mice in the three micelle treatment groups were all faster than those of 


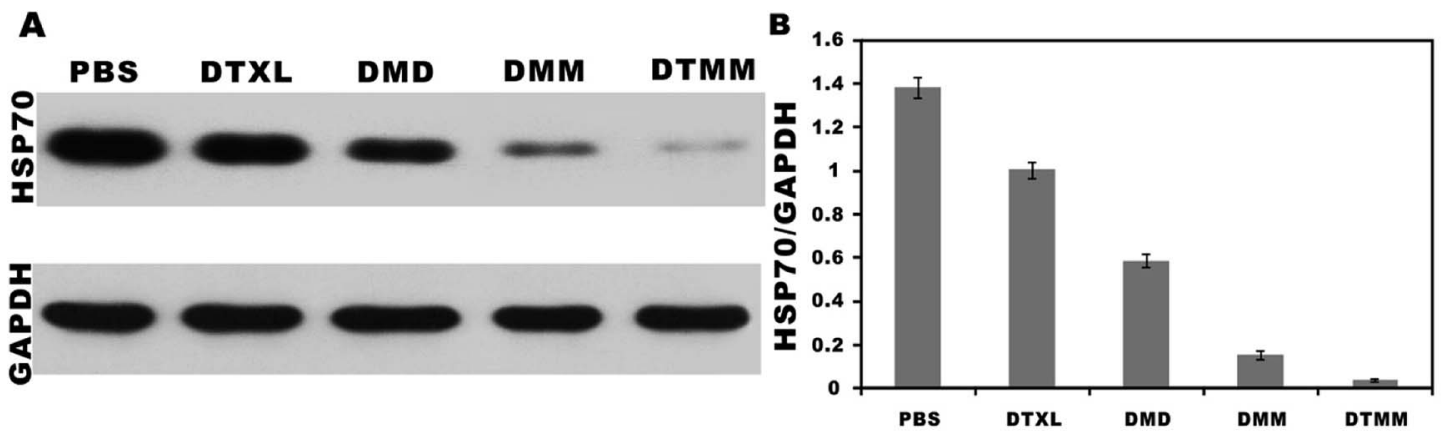

Fig. 8 Expression level of HSP70 detected by western blot in different treated tumors. The results are presented as the mean \pm SD $(n=3)$.

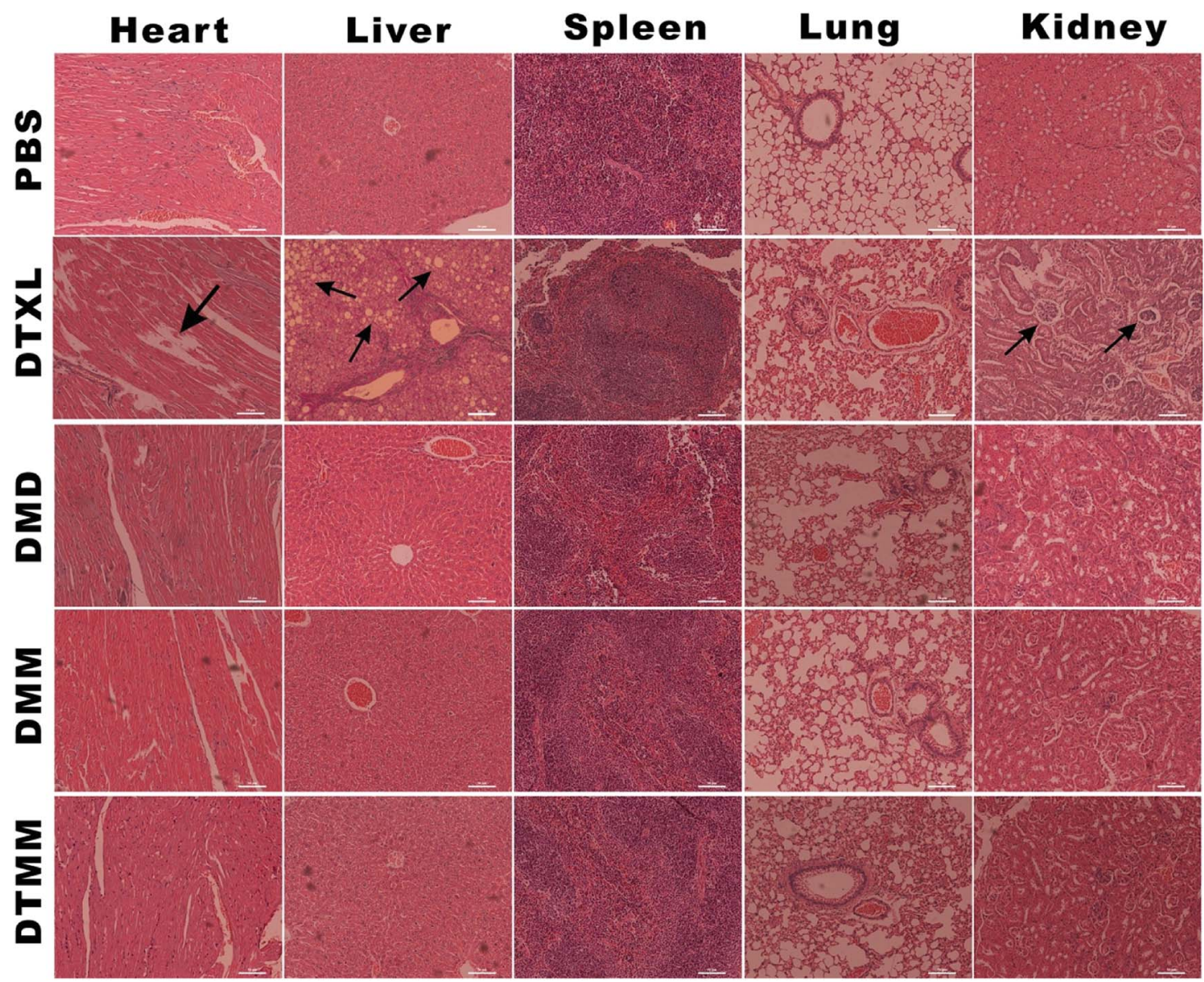

Fig. 9 Histological analysis by H\&E staining of major organs (heart, liver, spleen, lungs and kidneys) for the different treatments.

the docetaxel group (Fig. 7B), which may be due to the low toxicity of PLGA-PEG-Mal and the high toxicity of docetaxel. In addition, the growth rates of mouse weight in the DMM and DTMM groups were faster than that in the DMD group, revealing the better treatment efficiency of DMM and DTMM. In tumors treated with DMM and DTMM, partial or bulk necrotic cells were clearly observed over a broad area, and the number of necrotic cells was greater than that of DMD, especially for tumors treated with DTMM; this indicates the strong impact of apoptosis on cancer cells for the drug-loaded micelles based on microfluidics (Fig. 7E). In contrast, in the control group, the cancer cells were well grown, with intact cell nuclei and good differentiation. These results demonstrated that micelles based on microfluidics provide highly efficient delivery of chemotherapeutic drugs for cancer treatment.

\subsection{Micelles based on microfluidics inhibit the expression of HSP70}

The heat shock protein 70 family are highly conserved proteins that can act as molecular chaperones and transporters. HSP70 
plays an important role in carcinogenesis, promotes cancer cell proliferation, invasion, and metastasis, and inhibits apoptosis. $^{71}$ HSP70 may serve as a potential prognostic biomarker and therapeutic target for cancer. ${ }^{71,72}$ In the present study, western blots were performed to evaluate the expression level of HSP70. Tumors treated with PBS had the highest expression levels of HSP70, whereas the lowest expression level of HPS70 was observed in the DTMM group (Fig. 8). The expression levels of HPS70 in both the DMM and DTMM groups were lower than those in the DTXL and DMD groups $(P<0.05)$. These results indicate that the micelles based on microfluidics have a more significant inhibitory effect on the expression of tumor-associated proteins.

\subsection{In vivo toxicity assessment}

Histological analysis with H\&E staining was performed to study the toxicities of free docetaxel and the micelles. As shown in Fig. 9, after treatment with free docetaxel, an obvious breakdown of cardiac myocytes was observed in heart tissue; there were evident ballooning degeneration and fatty changes of hepatocytes in liver tissue; in kidney tissue, the chromatin condensed and the capillary loops expanded, and the glomerulus underwent atrophy. However, no obvious abnormal pathological changes in tissues were observed in mice treated with the micelles. These results indicate that the PLGA-PEG-Malbased micelles have little toxicity to normal organs because of the good biocompatibility of PLGA-PEG-Mal and the sustained release performance of the micelles.

\section{Conclusions}

In this study, docetaxel micelles based on PLGA-PEG-Mal were developed through microfluidics and a dialysis method, respectively. Compared with the micelles prepared by the dialysis method, the micelles produced by microfluidics have remarkable advantages in their physical properties, such as smaller particle size, narrower size distribution, higher drug loading efficiency, and better sustained release. The micelles prepared by microfluidics showed stronger effects on cancer cells and notable antitumor efficacy. Additionally, the polypeptide RGDfK was modified on the surfaces of the nanoparticles because it has potent targeting effects on cancer cells that express integrin $\alpha v \beta 3 .^{53}$ More encouragingly, PLGA-PEGMal has low toxicity as well as superior biodegradability. All these findings demonstrate that micelles based on microfluidics are a promising delivery system for incorporating multiple anticancer drugs for lung cancer treatment.

\section{Conflicts of interest}

The authors report no conflicts of interest in this work.

\section{Acknowledgements}

This work was financially supported by research grants from the National Natural Science Foundation of China (Grant No.
81301994) and the Natural Science Foundation of Shanghai City (No. 13ZR1434700) for Dr Zhou Songwen.

\section{References}

1 R. L. Siegel, K. D. Miller and A. Jemal, Cancer statistics, 2018, Ca-Cancer J. Clin., 2018, 68(1), 7-30.

2 J. R. Brahmer, R. Govindan, R. A. Anders, S. J. Antonia, S. Sagorsky, M. J. Davies, S. M. Dubinett, A. Ferris, L. Gandhi, E. B. Garon, et al., The Society for Immunotherapy of Cancer consensus statement on immunotherapy for the treatment of non-small cell lung cancer (NSCLC), Immunother. Cancer, 2018, 6(1), 75.

3 M. Alsharedi, H. Bukamur and A. Elhamdani, Osimertinib for the treatment of patients with EGFR mutation-positive non-small cell lung cancer, Drugs Today, 2018, 54(6), 369379.

4 L. Ventzel, A. B. Jensen, A. R. Jensen, T. S. Jensen and N. B. Finnerup, Chemotherapy-induced pain and neuropathy: a prospective study in patients treated with adjuvant oxaliplatin or docetaxel, Pain, 2016, 157(3), 560568.

5 A. Wicki, D. Witzigmann, V. Balasubramanian and J. Huwyler, Nanomedicine in cancer therapy: challenges, opportunities, and clinical applications, J. Controlled Release, 2015, 200, 138-157.

6 J. I. Hare, T. Lammers, M. B. Ashford, S. Puri, G. Storm and S. T. Barry, Challenges and strategies in anti-cancer nanomedicine development: an industry perspective, Adv. Drug Delivery Rev., 2017, 108, 25-38.

7 R. R. Costa, M. Alatorre-Meda and J. F. Mano, Drug nanoreservoirs synthesized using layer-by-layer technologies, Biotechnol. Adv., 2015, 33(6), 1310-1326.

8 S. Y. Qin, A. Q. Zhang, S. X. Cheng, L. Rong and X. Z. Zhang, Drug self-delivery systems for cancer therapy, Biomaterials, 2017, 112, 234-247.

9 T. J. Anchordoquy, Y. Barenholz, D. Boraschi, M. Chorny, P. Decuzzi, M. A. Dobrovolskaia, Z. S. Farhangrazi, D. Farrell, A. Gabizon, H. Ghandehari, et al., Mechanisms and Barriers in Cancer Nanomedicine: Addressing Challenges, Looking for Solutions, ACS Nano, 2017, 11(1), 12-18.

10 A. R. Kirtane, T. Sadhukha, H. Kim, V. Khanna, B. Koniar and J. Panyam, Fibrinolytic Enzyme Cotherapy Improves Tumor Perfusion and Therapeutic Efficacy of Anticancer Nanomedicine, Cancer Res., 2017, 77(6), 1465-1475.

11 S. Vahid, D. Thaper and A. Zoubeidi, Chaperoning the Cancer: The Proteostatic Functions of the Heat Shock Proteins in Cancer, Recent Pat. Anti-Cancer Drug Discovery, 2017, 12(1), 35-47.

12 K. Kataoka, A. Harada and Y. Nagasaki, Block copolymer micelles for drug delivery: design, characterization and biological significance, Adv. Drug Delivery Rev., 2001, 47(1), 113-131.

13 Z. A. Aziz, A. Ahmad, S. H. Mohd-Setapar, H. Hassan, M. A. Kamal and G. M. Ashraf, Recent advances in drug 
delivery of polymeric nano-micelles, Curr. Drug Metab., 2016, 18(1), 16-29.

14 J. Shi, P. W. Kantoff, R. Wooster and O. C. Farokhzad, Cancer nanomedicine: progress, challenges and opportunities, Nat. Rev. Cancer, 2017, 17(1), 20-37.

15 N. Nishiyama and K. Kataoka, Current state, achievements, and future prospects of polymeric micelles as nanocarriers for drug and gene delivery, Pharmacol. Ther., 2006, 112(3), 630-648.

16 B. K. Johnson and R. K. Prud'homme, Mechanism for rapid self-assembly of block copolymer nanoparticles, Phys. Rev. Lett., 2003, 91(11), 118302.

17 T. Chen, A. P. Hynninen, R. K. Prud'homme, I. G. Kevrekidis and A. Z. Panagiotopoulos, Coarse-grained simulations of rapid assembly kinetics for polystyrene- $b$-poly(ethylene oxide) copolymers in aqueous solutions, J. Phys. Chem. B, 2008, 112(51), 16357-16366.

18 P. M. Valencia, O. C. Farokhzad, R. Karnik and R. Langer, Microfluidic technologies for accelerating the clinical translation of nanoparticles, Nat. Nanotechnol., 2012, 7(10), 623-629.

19 V. P. Torchilin, Targeted polymeric micelles for delivery of poorly soluble drugs, Cell. Mol. Life Sci., 2004, 61(19-20), 2549-2559.

20 Y. Bae, N. Nishiyama, S. Fukushima, H. Koyama, M. Yasuhiro and K. Kataoka, Preparation and biological characterization of polymeric micelle drug carriers with intracellular $\mathrm{pH}$-triggered drug release property: tumor permeability, controlled subcellular drug distribution, and enhanced in vivo antitumor efficacy, Bioconjugate Chem., 2005, 16(1), 122-130.

21 T. Shen, S. Guan, Z. Gan, G. Zhang and Q. Yu, Polymeric Micelles with Uniform Surface Properties and Tunable Size and Charge: Positive Charges Improve Tumor Accumulation, Biomacromolecules, 2016, 17(5), 1801-1810.

22 T. S. Anirudhan, J. Parvathy and A. S. Nair, A novel composite matrix based on polymeric micelle and hydrogel as a drug carrier for the controlled release of dual drugs, Carbohydr. Polym., 2016, 136, 1118-1127.

23 C. C. Cheng, I. H. Lin, J. K. Chen, Z. S. Liao, J. J. Huang, D. J. Lee and Z. Xin, Nucleobase-Functionalized Supramolecular Micelles with Tunable Physical Properties for Efficient Controlled Drug Release, Macromol. Biosci., 2016, 16(10), 1415-1421.

24 S. Mohamed, N. N. Parayath, S. Taurin and K. Greish, Polymeric nano-micelles: versatile platform for targeted delivery in cancer, Ther. Delivery, 2014, 5(10), 1101-1121.

25 Q. Feng, J. Liu, X. Li, Q. Chen, J. Sun, X. Shi, B. Ding, H. Yu, Y. Li and X. Jiang, One-Step Microfluidic Synthesis of Nanocomplex with Tunable Rigidity and Acid-Switchable Surface Charge for Overcoming Drug Resistance, Small, 2017, 13(9), 1603109.

26 A. Nikoubashman, Self-assembly of colloidal micelles in microfluidic channels, Soft Matter, 2016, 13(1), 222-229.

27 J. Astorga-Wells, S. Vollmer, T. Bergman and H. Jornvall, Microfluidic systems and proteomics: applications of the electrocapture technology to protein and peptide analysis, Anal. Biochem., 2005, 345(1), 10-17.

$28 \mathrm{Z}$. Xu, C. Lu, J. Riordon, D. Sinton and M. G. Moffitt, Microfluidic Manufacturing of Polymeric Nanoparticles: Comparing Flow Control of Multiscale Structure in SinglePhase Staggered Herringbone and Two-Phase Reactors, Langmuir, 2016, 32(48), 12781-12789.

29 D. Eicher and C. A. Merten, Microfluidic devices for diagnostic applications, Expert Rev. Mol. Diagn., 2011, 11(5), 505-519.

30 K. B. Neeves, C. T. Lo, C. P. Foley, W. M. Saltzman and W. L. Olbricht, Fabrication and characterization of microfluidic probes for convection enhanced drug delivery, J. Controlled Release, 2006, 111(3), 252-262.

31 Y. Bae and K. Kataoka, Intelligent polymeric micelles from functional poly(ethylene glycol)-poly(amino acid) block copolymers, Adv. Drug Delivery Rev., 2009, 61(10), 768-784.

32 H. S. Yoo and T. G. Park, Biodegradable polymeric micelles composed of doxorubicin conjugated PLGA-PEG block copolymer, J. Controlled Release, 2001, 70(1-2), 63-70.

33 G. T. Chang, C. Li, W. Y. Lu and J. D. Ding, N-Boc-HistidineCapped PLGA-PEG-PLGA as a Smart Polymer for Drug Delivery Sensitive to Tumor Extracellular pH, Macromol. Biosci., 2010, 10(10), 1248-1256.

34 P. Zhang, H. Zhang, W. He, D. Zhao, A. Song and Y. Luan, Disulfide-Linked Amphiphilic Polymer-Docetaxel Conjugates Assembled Redox-Sensitive Micelles for Efficient Antitumor Drug Delivery, Biomacromolecules, 2016, 17(5), 1621-1632.

35 K. T. Cheng, N-[2-(4-[(18)F]Fluorobenzamido)ethyl $]$ maleimide-sulfhydryl-cyclic-arginine-glycine-aspartic acid peptide, in. Molecular Imaging and Contrast Agent Database (MICAD), Bethesda (MD), 2004.

$36 \mathrm{~W}$. Muangsiri and L. E. Kirsch, The protein-binding and drug release properties of macromolecular conjugates containing daptomycin and dextran, Int. J. Pharm., 2006, 315(1-2), 30-43.

37 R. Zhang, A. Bowyer, R. Eisenthal and J. Hubble, A smart membrane based on an antigen-responsive hydrogel, Biotechnol. Bioeng., 2007, 97(4), 976-984.

38 Y. Y. Li, X. Z. Zhang, H. Cheng, J. L. Zhu, U. N. Li, S. X. Cheng and R. X. Zhuo, Fluorescent, thermo-responsive biotin$\mathrm{P}(\mathrm{NIPAAm}-c o$-NDAPM)- $b$-PCL micelles for cell-tracking and drug delivery, Nanotechnology, 2007, 18(50), 505101.

39 H. Yan, J. Song, X. Jia and Z. Zhang, Hyaluronic acidmodified didecyldimethylammonium bromide/d-atocopheryl polyethylene glycol succinate mixed micelles for delivery of baohuoside I against non-small cell lung cancer: in vitro and in vivo evaluation, Drug Delivery, 2017, 24(1), 30-39.

40 W. Li, C. Zheng, Z. Pan, C. Chen, D. Hu, G. Gao, S. Kang, H. Cui, P. Gong and L. Cai, Smart hyaluronidase-actived theranostic micelles for dual-modal imaging guided photodynamic therapy, Biomaterials, 2016, 101, 10-19.

41 T. Jiang, C. Zhang, X. Zheng, X. Xu, X. Xie, H. Liu and S. Liu, Noninvasively characterizing the different alphavbeta3 expression patterns in lung cancers with RGD-USPIO using 
a clinical 3.0T MR scanner, Int. J. Nanomed., 2009, 4, 241249.

42 N. Ozdemir, Y. Ravindranath and S. Savasan, Cell-mediated cytotoxic evaluation using monoclonal antibody staining for target or effector cells with annexinV/propidium iodide colabeling by fluorosphere-adjusted counts on three-color flow cytometry, Cytometry, Part A, 2003, 56a(1), 53-60.

43 H. J. Yu, Z. A. Xu, D. G. Wang, X. Z. Chen, Z. W. Zhang, Q. Yin and $\mathrm{Y}$. P. Li, Intracellular $\mathrm{pH}$-activated PEG- $b$-PDPA wormlike micelles for hydrophobic drug delivery, Polym. Chem., 2013, 4(19), 5052-5055.

44 G. Gaucher, M. H. Dufresne, V. P. Sant, N. Kang, D. Maysinger and J. C. Leroux, Block copolymer micelles: preparation, characterization and application in drug delivery, J. Controlled Release, 2005, 109(1-3), 169-188.

45 J. E. Chung, M. Yokoyama and T. Okano, Inner core segment design for drug delivery control of thermo-responsive polymeric micelles, J. Controlled Release, 2000, 65(1-2), 93103.

46 C. J. Rijcken, O. Soga, W. E. Hennink and C. F. van Nostrum, Triggered destabilisation of polymeric micelles and vesicles by changing polymers polarity: an attractive tool for drug delivery, J. Controlled Release, 2007, 120(3), 131-148.

47 K. M. Huh, S. C. Lee, Y. W. Cho, J. Lee, J. H. Jeong and K. Park, Hydrotropic polymer micelle system for delivery of paclitaxel, J. Controlled Release, 2005, 101(1-3), 59-68.

48 P. Rafiei and A. Haddadi, Docetaxel-loaded PLGA and PLGAPEG nanoparticles for intravenous application: pharmacokinetics and biodistribution profile, Int. J. Nanomed., 2017, 12, 935-947.

49 Q. Feng, L. Zhang, C. Liu, X. Li, G. Hu, J. Sun and X. Jiang, Microfluidic based high throughput synthesis of lipidpolymer hybrid nanoparticles with tunable diameters, Biomicrofluidics, 2015, 9(5), 052604.

50 W. F. Bowers, S. Fulton and J. Thompson, Ultrafiltration vs. equilibrium dialysis for determination of free fraction, Clin. Pharmacokinet., 1984, 9(Suppl. 1), 49-60.

51 Q. B. Xu, M. Hashimoto, T. T. Dang, T. Hoare, D. S. Kohane, G. M. Whitesides, R. Langer and D. G. Anderson, Preparation of Monodisperse Biodegradable Polymer Microparticles Using a Microfluidic Flow-Focusing Device for Controlled Drug Delivery, Small, 2009, 5(13), 1575-1581.

52 Y. Zhang, H. F. Chan and K. W. Leong, Advanced materials and processing for drug delivery: the past and the future, Adv. Drug Delivery Rev., 2013, 65(1), 104-120.

53 Y. Miura, T. Takenaka, K. Toh, S. R. Wu, H. Nishihara, M. R. Kano, Y. Ino, T. Nomoto, Y. Matsumoto, H. Koyama, et al., Cyclic RGD-Linked Polymeric Micelles for Targeted Delivery of Platinum Anticancer Drugs to Glioblastoma through the Blood-Brain Tumor Barrier, ACS Nano, 2013, $7(10), 8583-8592$.

54 B. Liu, Y. Feng, J. Y. Zhang, H. M. Li, X. D. Li, H. L. Jia, Z. Y. Li and J. Feng, Imaging of bronchioloalveolar carcinoma in the mice with the alphabeta3 integrin-targeted tracer $(99 \mathrm{~m}) \mathrm{Tc}$ RGD-4CK, Transl. Res., 2013, 162(3), 174-180.

55 A. von Wallbrunn, C. Holtke, M. Zuhlsdorf, W. Heindel, M. Schafers and C. Bremer, In vivo imaging of integrin alpha nu beta(3) expression using fluorescence-mediated tomography, Eur. J. Nucl. Med. Mol. Imaging, 2007, 34(5), 745-754.

56 L. Zhang, G. Li, M. Gao, X. Liu, B. Ji, R. Hua, Y. Zhou and Y. Yang, RGD-peptide conjugated inulin-ibuprofen nanoparticles for targeted delivery of Epirubicin, Colloids Surf., B, 2016, 144, 81-89.

57 S. H. Park, J. H. Zheng, V. H. Nguyen, S. N. Jiang, D. Y. Kim, M. Szardenings, J. H. Min, Y. Hong, H. E. Choy and J. J. Min, RGD Peptide Cell-Surface Display Enhances the Targeting and Therapeutic Efficacy of Attenuated Salmonellamediated Cancer Therapy, Theranostics, 2016, 6(10), 16721682.

58 I. J. Fang, I. I. Slowing, K. C. Wu, V. S. Lin and B. G. Trewyn, Ligand conformation dictates membrane and endosomal trafficking of arginine-glycine-aspartate (RGD)functionalized mesoporous silica nanoparticles, Chemistry, 2012, 18(25), 7787-7792.

59 W. Fei, Y. Zhang, S. Han, J. Tao, H. Zheng, Y. Wei, J. Zhu, F. Li and X. Wang, RGD conjugated liposome-hollow silica hybrid nanovehicles for targeted and controlled delivery of arsenic trioxide against hepatic carcinoma, Int. J. Pharm., 2017, 519(1-2), 250-262.

60 X. B. Xiong, Y. Huang, W. L. Lu, X. Zhang, H. Zhang, T. Nagai and Q. Zhang, Intracellular delivery of doxorubicin with RGD-modified sterically stabilized liposomes for an improved antitumor efficacy: In vitro and in vivo, J. Pharm. Sci., 2005, 94(8), 1782-1793.

61 J. D. Humphries, A. Byron and M. J. Humphries, Integrin ligands at a glance, J. Cell Sci., 2006, 119(19), 3901-3903.

62 X. Yi, Y. Ding, Y. Zeng, C. Zhou, B. Luo, S. Meng, W. Rui, Y. Zhao and W. Li, Magnetic resonance imaging contrast agent: cRGD-ferric oxide nanometer particle and its role in the diagnosis of tumor, J. Nanosci. Nanotechnol., 2011, 11(5), 3800-3807.

63 B. Chen, W. Zhang, B. Ji, Q. Ma, D. Li and S. Gao, Integrin alphaVbeta3-targeted SPECT/CT for the assessment of Bevacizumab therapy in orthotopic lung cancer xenografts, Oncol. Lett., 2018, 15(4), 4201-4206.

64 S. Meng, B. Su, W. Li, Y. Ding, L. Tang, W. Zhou, Y. Song and Z. Caicun, Integrin-targeted paclitaxel nanoliposomes for tumor therapy, Med. Oncol., 2011, 28(4), 1180-1187.

65 M. Qiu, H. Sun, F. Meng, R. Cheng, J. Zhang, C. Deng and Z. Zhong, Lipopepsomes: A novel and robust family of nano-vesicles capable of highly efficient encapsulation and tumor-targeted delivery of doxorubicin hydrochloride in vivo, J. Controlled Release, 2018, 272, 107-113.

66 C. Khemtong, C. W. Kessinger, J. Ren, E. A. Bey, S. G. Yang, J. S. Guthi, D. A. Boothman, A. D. Sherry and J. Gao, In vivo off-resonance saturation magnetic resonance imaging of alphavbeta3-targeted superparamagnetic nanoparticles, Cancer Res., 2009, 69(4), 1651-1658.

67 M. Griese and D. Reinhardt, Smaller sized particles are preferentially taken up by alveolar type II pneumocytes, $J$. Drug Targeting, 1998, 5(6), 471-479.

68 K. Zeller Meidell, R. Robinson, A. Vieira-de-Abreu, A. J. Gormley, H. Ghandehari, D. W. Grainger and 
R. A. Campbell, RGDfK-functionalized gold nanorods bind only to activated platelets, J. Biomed. Mater. Res., Part A, 2017, 105(1), 209-217.

69 A. Eldar-Boock, R. Blau, C. Ryppa, H. Baabur-Cohen, A. Many, M. J. Vicent, F. Kratz, J. Sanchis and R. SatchiFainaro, Integrin-targeted nano-sized polymeric systems for paclitaxel conjugation: a comparative study, J. Drug Targeting, 2017, 25(9-10), 829-844.

70 J. Ochando, W. H. Kwan, F. Ginhoux, J. A. Hutchinson, D. Hashimoto and M. Collin, The Mononuclear Phagocyte System in Organ Transplantation, Am. J. Transplant., 2016, 16(4), 1053-1069.
71 N. Taghavi, Z. Mohsenifar, A. A. Baghban and A. Arjomandkhah, CD20+ Tumor Infiltrating B Lymphocyte in Oral Squamous Cell Carcinoma: Correlation with Clinicopathologic Characteristics and Heat Shock Protein 70 Expression, J. Pathol. Res. Int., 2018, 2018, 4810751.

72 J. A. Yaglom, Y. Wang, A. Li, Z. Li, S. Monti, I. Alexandrov, X. Lu and M. Y. Sherman, Cancer cell responses to Hsp70 inhibitor JG-98: Comparison with Hsp90 inhibitors and finding synergistic drug combinations, Sci. Rep., 2018, 8(1), 3010 . 